ISSN: 0514-7336

DOI: http://dx.doi.org/10.14201/zephyrus201677147172

\title{
PINTURA MURAL ROMANA EN ÁMBITO DOMÉSTICO DURANTE EL S. I d. C. EN EL CONVENTUS CAESARAUGUSTANUS
}

\section{Roman wall painting in domestic environments of the conventus Caesaraugustanus}

\author{
Lara ÍNIGUEz BERROZPE \\ Grupo de Investigación URBS. Escuela de Turismo Universitaria de Zaragoza. Plaza Ecce Homo, 3. 50003 Zaragoza. \\ Correo-e:laraib@unizar.es
}

Recepción: 22/03/2015; Revisión: 6/07/2015; Aceptación: 4/09/2015

\begin{abstract}
Resumen: Presentamos un análisis de los restos pictóricos hallados en los ambientes domésticos del conventus Caesaraugustanus, fechados en el s. I d. C. El estudio, basado en una metodología a través de la cual hemos examinado los aspectos técnicos y estilísticos de los fragmentos procedentes del ámbito doméstico de nueve yacimientos insertos en dicho territorio, nos ha permitido profundizar en el conocimiento tanto de la representación del III y iv estilos pompeyanos en el mundo provincial como de los talleres de artesanos encargados de enlucir las estancias. Los restos decorativos también nos han permitido acercarnos a los comitentes que seleccionaron determinados motivos ornamentales para sus viviendas. A partir de ello nos planteamos si es posible documentar, a través de la pintura mural romana y en el territorio que nos ocupa, la mutación social acaecida en la Península Ibérica con la llegada de Augusto, siempre teniendo en cuenta el sustrato indígena precedente y el fuerte impulso que en este momento alcanzó el proceso de adhesión a la nueva cultura.

Palabras clave: Domus; decoración; estilos pompeyanos; talleres; comitentes.
\end{abstract}

ABSTRACT: We present an analysis of pictorial remains found in domestic environments of conventus Caesaraugustanus, dated in the first century $\mathrm{AD}$. The study, based on a methodology through which we examined the technical and stylistic aspects of the fragments from the domestic sphere of nine sites located in that territory, has allowed us to deepen the understanding of both the representation of III and IV Pompeian styles in the provincial world, and craft workshops that made them. The decorative remains will also bring us out to those patrons who selected certain ornamental motives for their homes. So, we will consider whether it is possible to document, through the Roman wall painting and in the territory concerned, the social mutation occurred in the Iberian Peninsula with the advent of Augustus, taking into account the precedent indigenous substrate and the strong impulse that the accession process to the new culture reached at this time.

Keywords: Domus; decoration; Pompeian styles; painter-workshop; patrons.

\section{Introducción ${ }^{1}$}

El área geográfica que ocupó el conventus iuridicus Caesarangustanus (Fig. 1) fue un territorio de

${ }^{1}$ Este trabajo se enmarca dentro del proyecto de investigación La decoración parietal en el cuadrante NE de Hispania: pinturas y estucos (ss. II a. C. -VI d. C.) HAR2OI 3-48456-C3-2-P dirigido por C. Guiral Pelegrín. El punto de partida del análisis gran interés para Roma desde el momento en el que se inició la conquista de la Península Ibérica. Durante la República, diversos episodios bélicos no hicieron sino aumentar la presencia militar, pero también

que presentamos han sido los materiales estudiados en nuestra tesis doctoral: La pintura mural romana de ámbito doméstico en el conventus Caesaraugustanus durante el s. I d. C.: talleres y comitentes, defendida en 2014 en la Univ. de Zaragoza. 


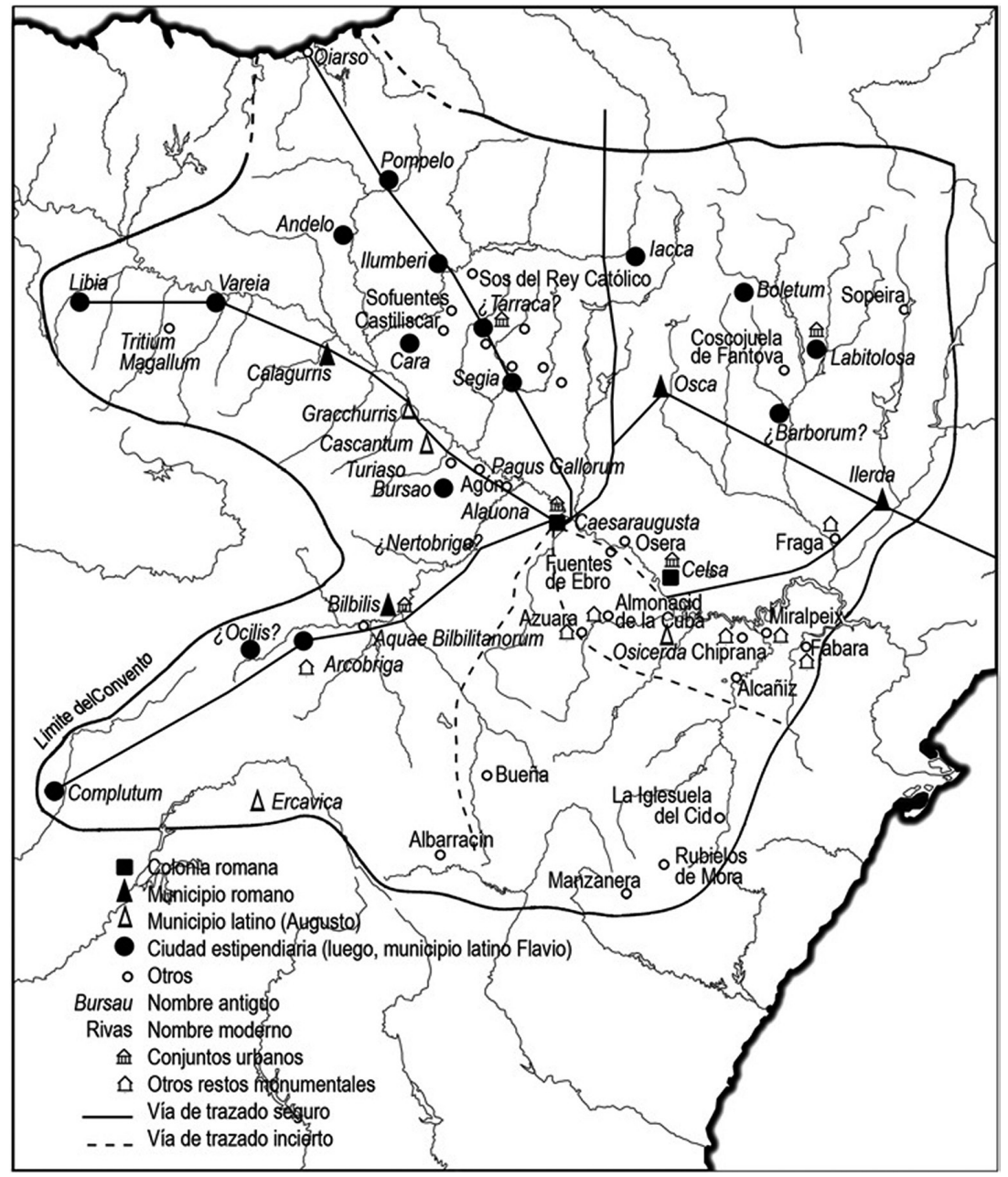

Fig. 1. Conventus Caesaraugustanus (Beltrán, 2012). culminó en época flavia, ya que fue durante el reinado de Vespasiano cuando se concedió a las tres provincias existentes en ese momento en Hispania el derecho latino. En el área geográfica que nos ocupa es ahora cuando enclaves como Arcobriga, Labitolosa o Los Bañales - probable Tarraca- alcanzaron el estatus de municipium (Beltrán et al., 2000; Galve et al., 2005).

Así pues, hablamos de un territorio en el que la influencia de la cultura romana se deja sentir en época muy temprana. Desde estos primeros contactos hasta la llegada de Augusto, verdadero punto de inflexión, el fenómeno de adaptación, previo a la integración política total, y también de síntesis -como corresponde a un territorio fronterizo en el que confluyeron íberos, celtas y vascones (Beltrán, 2000) - se plasmó en ciertas manifestaciones culturales, como la aparición de escritura en soporte duradero o la acuñación de moneda. Este fenómeno también se intuye en las decoraciones de ámbito domésti- cultural, de Roma, con la consecuente y progresiva instalación de la población itálica. Con la llegada de Augusto, y más concretamente con el proyecto llevado a cabo por Agripa, fue cuando este proceso de romanización se impulsó de manera imparable y, sobre todo, irreversible. Un buen número de ciudades peregrinas contarán a partir de ahora con un nuevo rango. Entre los ańos 15-14 a. C. la capital de la recién creada circunscripción administrativa, el conventus Caesaraugustanus, será la también colonia Caesar Augusta, erigida sobre la antigua Salduie. Núcleos como Osca, Bilbilis, Ilerda y, probablemente, Ercavica recibieron en este momento el rango municipal. Se trató de un proceso de integración que co. No olvidemos que es en el valle del Ebro donde encontramos los ejemplos más precoces del conocido como Estilo I que marcan la fecha de introducción de la pintura mural romana en nuestro país.

\section{Antecedentes}

Los restos exhumados en los yacimientos de $\mathrm{Se}$ geda, Azaila, Contrebia Belaisca, La Caridad y Valdeherrera, cuya cronología se extiende desde mediados del s. II a. C. hasta las guerras sertorianas, no sólo permitieron documentar los primeros opera signina del territorio, sino también las primeras decoraciones murales encuadradas dentro de ese Estilo I. 
La técnica, esquemas compositivos y ornamentos empleados revelan una clara procedencia externa de los talleres de artesanos que los realizaron y que, seguramente, respondieron a las demandas efectuadas por los primeros contingentes itálicos asentados en lo que más tarde sería el conventus Caesaraugustanus. Muros y pavimentos, además, se adecúan a las funcionalidades de las estancias: observamos en suelos y paredes de los dormitorios de Contrebia Belaisca y Valdeherrera, fundamentalmente, una bipartición según la cual $1 / 3$ es reservado para el lecho y $2 / 3$ se dedican a la antecámara, una costumbre que se mantendrá durante casi todo el s. I d.C. (Guiral y Mostalac, 2011).

Desde las guerras sertorianas hasta el ocaso de la primera mitad del s. I a. C. existe un vacío en lo que a producción pictórica se refiere. Por el momento no se han exhumado conjuntos encuadrables en las primeras fases del Estilo II. Este fenómeno no se observa en los pavimentos, ya que se siguen realizando opera signina sin solución de continuidad durante toda esta centuria. Ahora bien, los artesanos se tomaron algunas libertades en su realización, hecho que permite establecer la hipótesis de que los primeros talleres itálicos que llegaron al territorio que nos ocupa se marcharon, no sin que antes aprendieran de ellos artesanos locales que reprodujeron su técnica y repertorio, eso sí, con ciertas licencias (Guiral y Mostalac, 1993: 390; idem, 2011: 609; Beltrán y Mostalac, 2008: 115).

Hemos de esperar a la segunda mitad del s. I a. C. para que nuevos talleres itálicos lleguen al valle del Ebro. Particularmente representativas de un II Estilo canónico resultan las decoraciones de la Colonia Victrix Iulia Lepida/Celsa, con unas magníficas arquitecturas pintadas presentes en la estancia 13 de la Casa в (Mostalac y Beltrán, 1994: 120-123), у con el emblemático repertorio ornamental del salón triclinar de la Casa de Hércules (Mostalac y Beltrán, 1996). Dentro de esta misma vivienda, en las estancias 17 y 18 , se constató la presencia del denominado zocollo sporgente, un procedimiento funcional a través del cual la zona inferior se refuerza -haciendo que sobresalga y finalizándose en bisel- con el objetivo de aislar este sector y protegerlo de los perjudiciales cambios de temperatura que se producían en determinadas habitaciones (Mostalac y Beltrán, 1994: 58-61).

Recientemente también se han constatado hallazgos pictóricos de este periodo en el yacimiento de Bilbilis: en el tablinum (н. 11) de la Casa del Larario; en el cubiculum (H. 9) (Fig. 3c y d) y probablemente en la posible exedra (H. 10) de la Domus 1 (Guiral e Íñiguez, 2011: 80-81 y 85-86); y en el cubiculum hallado en la habitación almacén (н. 24) de la Domus 2 (Lope, 2007: 185-192).

Más esporádicos, aunque significativos en este sentido, han sido los restos decorativos del II Estilo exhumados en la c/ Don Juan de Aragón y en la cl Torrellas de la actual Zaragoza (Beltrán y Mostalac, 2008: 115).

\section{Principales conjuntos pictóricos del I d. C. en ambientes privados del conventus Caesaraugustanus ${ }^{2}$}

A partir de finales del s. I a. C., nuestro conocimiento sobre las decoraciones pictóricas se amplía notablemente. Los Estilos III y IV ${ }^{3}$ son los más representados en el conventus Caesaraugustanus. Sabemos que la introducción de las nuevas modas ornamentales se produjo sin ningún tipo de desfase temporal respecto a la península itálica, siendo el yacimiento de Caesar Augusta el lugar clave para establecer con rotundidad tal afirmación. Los restos exhumados en el Paseo Echegaray y Caballero de Zaragoza revelaron su pertenencia a una zona media decorada con estrechos filetes triples, blancos y violetas sobre un fondo negro -ornamento característico del III Estilo- acompañada de un zócalo moteado de fondo rosáceo. La novedad que supuso este hallazgo radica en lo siguiente: el nivel estratigráfico

2 En adelante se citarán los distintos conjuntos pictóricos usando las abreviaturas que aparecen en la Fig. 2. En dicha tabla se muestran los nueve yacimientos del conventus Caesaraugustanus donde, hasta el momento, se han exhumado conjuntos pictóricos procedentes de las estructuras domésticas que ahí se indican.

3 En términos estilísticos el s. I d. C. abarca los Estilos Pompeyanos III y IV, así como el comienzo del estilo provincial. 


\begin{tabular}{|c|c|c|c|c|c|c|c|}
\hline $\begin{array}{l}\text { PROCEDENCIA DEL } \\
\text { CONJUNTO }\end{array}$ & ABREVIATURA & $\begin{array}{l}\text { PROCEDENCIA DEL } \\
\text { CONJUNTO }\end{array}$ & ABREVIATURA & PROCEDENCIA DEL CONJUNTO & ABREVATURA & $\begin{array}{l}\text { PROCEDENCIA DEL } \\
\text { CONJUNTO }\end{array}$ & ABREVIATURA \\
\hline \multicolumn{2}{|c|}{ COLONIA CAESAR AUGUSTA } & \multicolumn{2}{|c|}{ MUNICIPIUM AUGUSTA BILBILIS } & \multicolumn{2}{|c|}{ COLONIA VICTRIX IULIA CELSA } & \multicolumn{2}{|l|}{ LABITOLOSA } \\
\hline $\begin{array}{l}\text { Domus Calle Añón. } \\
\text { Triclinium. Paredes }\end{array}$ & Caes. 1 & $\begin{array}{l}\text { Domus 1. Balneum } \\
\text { (H.3) }\end{array}$ & Bil. 1 & $\begin{array}{l}\text { Casa C o Domus de los } \\
\text { Delfines. Pasillo } 1\end{array}$ & Cel. 1 & $\begin{array}{l}\text { Vivienda anterior a la Domus } \\
\text { 1. Fragmentos }\end{array}$ & Lab. 1 \\
\hline $\begin{array}{l}\text { Domus Calle Añón. } \\
\text { Triclinium. Techo }\end{array}$ & Caes. 2 & $\begin{array}{l}\text { Domus 1. Tablimum } \\
\text { (H.4) }\end{array}$ & Bil. 2 & $\begin{array}{l}\text { Casa C o Domus de los } \\
\text { Delfines. Patio } 2\end{array}$ & Cel. 2 & $\begin{array}{l}\text { Vivienda anterior a la Domus } \\
\text { 1. Fragmentos }\end{array}$ & Lab. 2 \\
\hline Domus Paseo Echegaray & Caes. 3 & $\begin{array}{l}\text { Domus 3. Relleno de la } \\
\text { taberna H.27 }\end{array}$ & Bil. 3 & $\begin{array}{l}\text { Casa C o Domus de los } \\
\text { Delfines. Estancia } 4\end{array}$ & Cel. 3 & $\begin{array}{l}\text { Vivienda anterior a la Domus } \\
\text { 1. Fragmentos }\end{array}$ & Lab. 3 \\
\hline $\begin{array}{l}\text { Domus Calle de la } \\
\text { Rebolería }\end{array}$ & Caes. 4 & $\begin{array}{l}\text { Domus 3. Panel in situ } \\
\text { entre el patio porticado } \\
\text { (H.32) y la estancia }\end{array}$ & Bil. 4 & $\begin{array}{l}\text { Casa C o Domus de los } \\
\text { Delfines. Estancia 6, pinturas } \\
\text { en estado fragmentario }\end{array}$ & Cel 4 & $\begin{array}{l}\text { Vivienda anterior a la Domus } \\
\text { 1. Fragmentos }\end{array}$ & Lab. 4 \\
\hline $\begin{array}{l}\text { Domus Calle Palomeque. } \\
\text { Larario }\end{array}$ & Caes. 5 & $\begin{array}{l}\text { Casa del Larario. Atrio } \\
\text { (H.6) }\end{array}$ & Bil 5 & $\begin{array}{l}\text { Casa C o Domus de los } \\
\text { Delfines. Estancia 6, pinturas } \\
\text { en estado fragmentario }\end{array}$ & Cel 5 & Domus 1. Habitación 1 & Lab. 5 \\
\hline $\begin{array}{l}\text { Domus Calle Palomeque. } \\
\text { Decoración in situ }\end{array}$ & Caes. 6 & $\begin{array}{l}\text { Casa del Larario. } \\
\text { Sacrarium (H.13) }\end{array}$ & Bil. 6 & $\begin{array}{l}\text { Casa C o Domus de los } \\
\text { Delfines. Estancia 6, pintura in } \\
\text { situ }\end{array}$ & Cel. 6 & Domus 1. Habitación 4 & Lab. 6 \\
\hline $\begin{array}{l}\text { Domus Calle } \\
\text { Predicadores }\end{array}$ & Caes. 7 & $\begin{array}{l}\text { Casa del Larario. Pasillo } \\
\text { (H.5) }\end{array}$ & Bil. 7 & $\begin{array}{l}\text { Casa C o Domus de los } \\
\text { Delfines. Estancia } 7\end{array}$ & Cel. 7 & & \\
\hline $\begin{array}{l}\text { Domus Calle Mayor } \\
\text { angular a Argensola }\end{array}$ & Caes. 8 & $\begin{array}{l}\text { Casa del Larario. } \\
\text { Conjunto desplomado } \\
\text { en H.1 }\end{array}$ & Bil. 8 & $\begin{array}{l}\text { Casa C o Domus de los } \\
\text { Delfines. Estancia } 8\end{array}$ & Cel 8 & & \\
\hline $\begin{array}{l}\text { Domus Avenida de César } \\
\text { Augusto con Gómez Ulla }\end{array}$ & Caes. 9 & $\begin{array}{l}\text { Casa del Larario. } \\
\text { Conjunto desplomado } \\
\text { en H.3 }\end{array}$ & Bil. 9 & $\begin{array}{l}\text { Casa C o Domus de los } \\
\text { Delfines. Estancia } 10\end{array}$ & Cel. 9 & & \\
\hline \multicolumn{2}{|c|}{ MUNICIPIUM URBS VICTRIX OSCA } & $\begin{array}{l}\text { Casa del Larario. } \\
\text { Conjunto desplomado } \\
\text { entre H.3 y H.2 }\end{array}$ & Bi. 10 & $\begin{array}{l}\text { Casa C o Domus de los } \\
\text { Delfines. Estancia } 12\end{array}$ & Cel. 10 & & \\
\hline Domus? Calle Dormer & Osc. 1 & $\begin{array}{l}\text { Casa del Larario. } \\
\text { Triclinium (H.4) }\end{array}$ & Bil. 11 & $\begin{array}{l}\text { Casa C o Domus de los } \\
\text { Delfines. Estancia } 14\end{array}$ & Cel. 11 & & \\
\hline Domus? Calle Dormer & Osc. 2 & $\begin{array}{l}\text { Sector C.IV. Relleno de } \\
\text { los espacios 7-9 }\end{array}$ & Bil. 12 & $\begin{array}{l}\text { Casa C o Domus de los } \\
\text { Delfines. Estancia 15a }\end{array}$ & Cel. 12 & & \\
\hline $\begin{array}{l}\text { Domus Calle Ainsa- } \\
\text { Ricafort }\end{array}$ & Osc. 3 & Casa de la Cisterna & Bil. 13 & $\begin{array}{l}\text { Casa C o Domus de los } \\
\text { Delfines. Estancia 15b }\end{array}$ & Cel. 13 & & \\
\hline \multicolumn{2}{|c|}{ MUNICIPIUM ILERDA } & Casa de las Escaleras. & Bil. 14 & $\begin{array}{l}\text { Casa } \mathrm{C} \text { o Domus de los } \\
\text { Delfines. Estancia } 16\end{array}$ & Cel. 14 & & \\
\hline $\begin{array}{l}\text { Domus de l'Antic Portal } \\
\text { de Magdalena }\end{array}$ & Ile. 1 & Casa de las Escaleras & Bil. 15 & $\begin{array}{l}\text { Casa C o Domus de los } \\
\text { Delfines. Estancia } 19\end{array}$ & Cel. 15 & & \\
\hline \multicolumn{2}{|c|}{ MUNICIPIUM ERCAVICA } & Casa de las Escaleras & Bil. 16 & \multicolumn{2}{|l|}{ ARCOBRIGA } & & \\
\hline Domus 4. Peristilo & Erc. 1 & $\begin{array}{l}\text { Casa de la Fortuna. } \\
\text { Larario }\end{array}$ & Bil. 17 & Casa del Pretorio & Arc. 1 & & \\
\hline $\begin{array}{l}\text { Domus 4. Estancia } \\
\text { republicana }\end{array}$ & Erc. 2 & Casa en el sector SPIII & Bil. 18 & Casa del Pretorio & Arc. 2 & & \\
\hline \multicolumn{2}{|c|}{ LOS BAÑALES } & $\begin{array}{l}\text { Termas. Conjunto } \\
\text { hallado en la estancia M }\end{array}$ & Bil. 19 & Casa del Pretorio & Arc. 3 & & \\
\hline $\begin{array}{l}\text { Casa del Peristilo. } \\
\text { Cubiculum }\end{array}$ & Bañ. 1 & \begin{tabular}{|l|} 
Termas. Conjunto \\
hallado en la estancia M
\end{tabular} & Bil. 20 & Casa del Pretorio & Arc. 4 & & \\
\hline $\begin{array}{l}\text { Casa del Peristilo. } \\
\text { Fragmentos en superficie }\end{array}$ & Bañ. 2 & $\begin{array}{l}\text { Termas. Techo hallado } \\
\text { en la estancia M }\end{array}$ & Bil. 21 & Casa del Pretorio & Arc. 5 & & \\
\hline & & $\begin{array}{l}\text { Termas. Conjunto } \\
\text { hallado en la estancia M }\end{array}$ & Bi. 22 & & & & \\
\hline
\end{tabular}

FIG. 2. Tabla de equivalencias entre el lugar de procedencia de los fragmentos pictóricos y las abreviaturas con las que se citan en el texto. 
en el que se encontraban indicaba que tales piezas estaban ya destruidas en la última década del s. I a. C., y por tanto pertenecían a un momento anterior. Teniendo en cuenta que el III Estilo comienza en la península itálica en torno al 15 a. C., estos fragmentos avalaban totalmente la teoría de la inexistencia del retraso cronológico de las decoraciones provinciales (Mostalac y Guiral, 1987: 183).

De los cuatro estilos pompeyanos, el in Estilo es la primera etapa del lapso temporal que hemos seleccionado. Debemos dejar patente que, con los restos que hoy conocemos y con los datos obtenidos acerca de las distintas excavaciones en las cuales fueron exhumados, no estamos en disposición de elaborar una clasificación basándonos en las fases y subfases en las que F. L. Bastet y M. de Vos lo dividieron ${ }^{4}$. Podemos, tal como afirmó A. Barbet ${ }^{5}, \mathrm{y}$ sólo en algunos casos, indicar su pertenencia a un periodo inicial, de desarrollo o de madurez. A esta advertencia debemos añadir el hecho de que tampoco hemos documentado conjuntos pertenecientes a los denominados "estilos de transición".

4 Su estudio es la principal obra de referencia sobre el III Estilo que dividieron en dos fases: la primera, desarrollada entre 20 y 25 d. C., consistente en una desaparición progresiva de los elementos decorativos de la parte media y su aislamiento dentro de la zona superior; la segunda, entre 25 y 45 d. C., presenta una heterogeneidad de ornamentos que darán paso al IV Estilo. Ambas se encuentran divididas en subfases -Ia, Ib, Ic; IIa y IIb- (Bastet y De Vos, 1979: 62-103).

5 Barbet (1985: 96-175) consideró que la diferencia se debía a la actuación de diversos talleres paralelos. Para esta autora sólo existirían tres grandes fases: la inicial caracterizada por la sustitución de columnas por candelabros y la presencia de paneles planos acordes con el clasicismo augústeo; el periodo de expansión, con tendencia hacia la monocromía; y el periodo de madurez, con construcciones arquitectónicas frágiles e irreales, ejecutado todo ello con colores claros. También señaló un periodo de transición hacia el Iv Estilo.

6 Serán dos fundamentalmente: uno de ellos se preocupará por hacer desaparecer progresivamente los elementos arquitectónicos tan característicos del estilo anterior sustituyéndolos por candelabros. El segundo, mantendrá dichas estructuras apostando así por cierto conservadurismo. En cualquier caso, los dos desembocarán en esta nueva moda que se extenderá por el Imperio.
Por el momento, contamos con decoraciones encuadrables en un III Estilo que, aunque no son totalmente independientes del periodo pictórico anterior, tal como ocurre en Roma y en las ciudades campanas (Guillaud, 1990: 45), sí suponen una reacción estética a ese II Estilo; esto se avala por sí mismo si comparamos, por ejemplo, las pesadas arquitecturas de los emblemáticos conjuntos celcenses de periodo republicano, con las pinturas que citaremos a continuación. Podemos decir que la cultura romana, coincidiendo con el punto de inflexión que supone el reinado de Augusto, trae a Hispania una novedosa moda pictórica basada en la tripartición de la pared y en nuevos ornamentos, que sólo pudo darse por el cambio en la concepción arquitectónica de las viviendas (Clarke, 1987: 267).

En el conventus Caesaraugustanus se pueden fechar en los primeros decenios de la Era los conjuntos de Caesar Augusta hallados en las estructuras domésticas exhumadas en el Paseo Echegaray [Caes. 3], en la c/ Rebolería [Caes. 4] y en la c/ Mayor angular a la c/ Hermanos Argensola [Caes. 8]; decoraciones que presentan, fundamentalmente, finos moteados y filetes triples sobre paneles planos (Mostalac y Guiral, 1987: 187-190).

También en Bilbilis se documentan varias pinturas que se pueden encuadrar dentro de esta primera etapa: los fragmentos del piso superior de la Casa del Larario descubiertos en el relleno de la estancia H. 3 [Bil. 9] y entre esta y la habitación contigua $\mathrm{H}$. 2 [Bil. 10] (Guiral y Martín-Bueno, 1996: 356364), que remiten a decoraciones basadas en finos moteados y sobrios paneles planos, decorados con columnas en el primer caso; las pinturas de uno de los cuatro conjuntos hallados en las termas ${ }^{7}$ [Bil. 22] (Fig. 8c), con una tosca imitación marmórea en su parte inferior, y paneles planos alternados con interpaneles oscuros ornados por finísimos candelabros metálicos en su zona media (Guiral y Martín-Bueno, 1996: 134-138); las piezas de la primera fase de la Casa de las Escaleras [Bil. 15], con paneles planos

\footnotetext{
7 Aunque fueron hallados en las termas, su lugar de origen probablemente esté en alguna de las domus que conforman la Insula I, a juzgar por la similitud técnica y decorativa de los conjuntos.
} 
a)

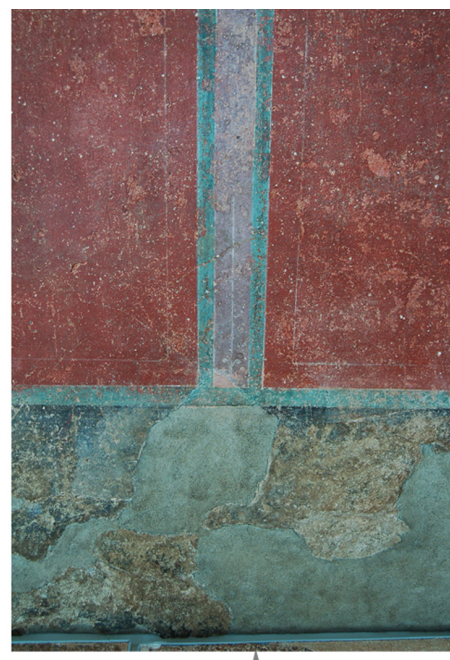

c)

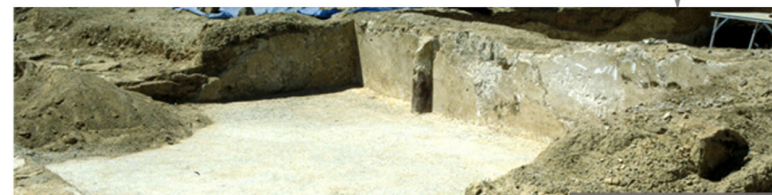

b)

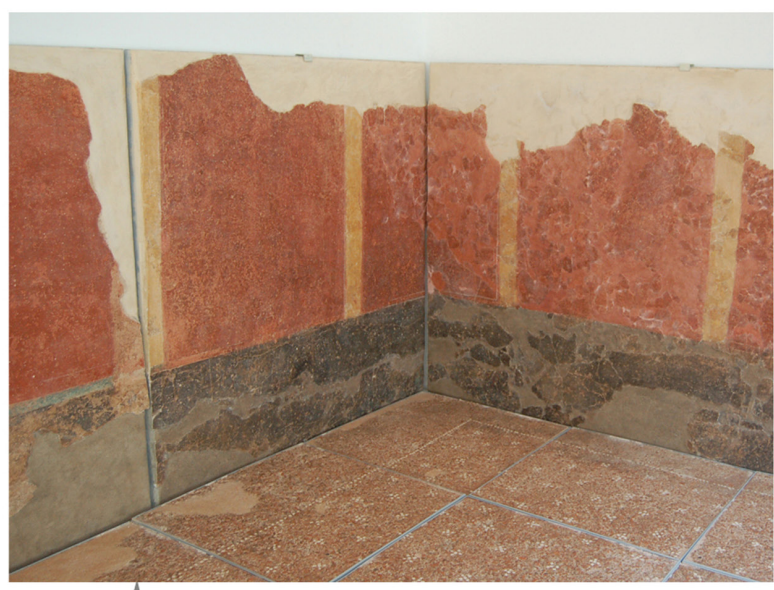

Fig. 3. Planta y restos pictóricos de la Domus 1 [Insula $I$ ] de Bilbilis: a) detalle de interpanel violáceo en la decoración del tablinum [Bil. 2] (Museo de Calatayud); b) vista general de la decoración del tablinum (fotog. de P. Uribe); c) vista del cubiculum [9] con columna adosada a la pared (archivo fotográfico excavación de Bilbilis); d) restitución del techo del cubiculum [9] (según $C$. Guiral y L. Íñiguez). 

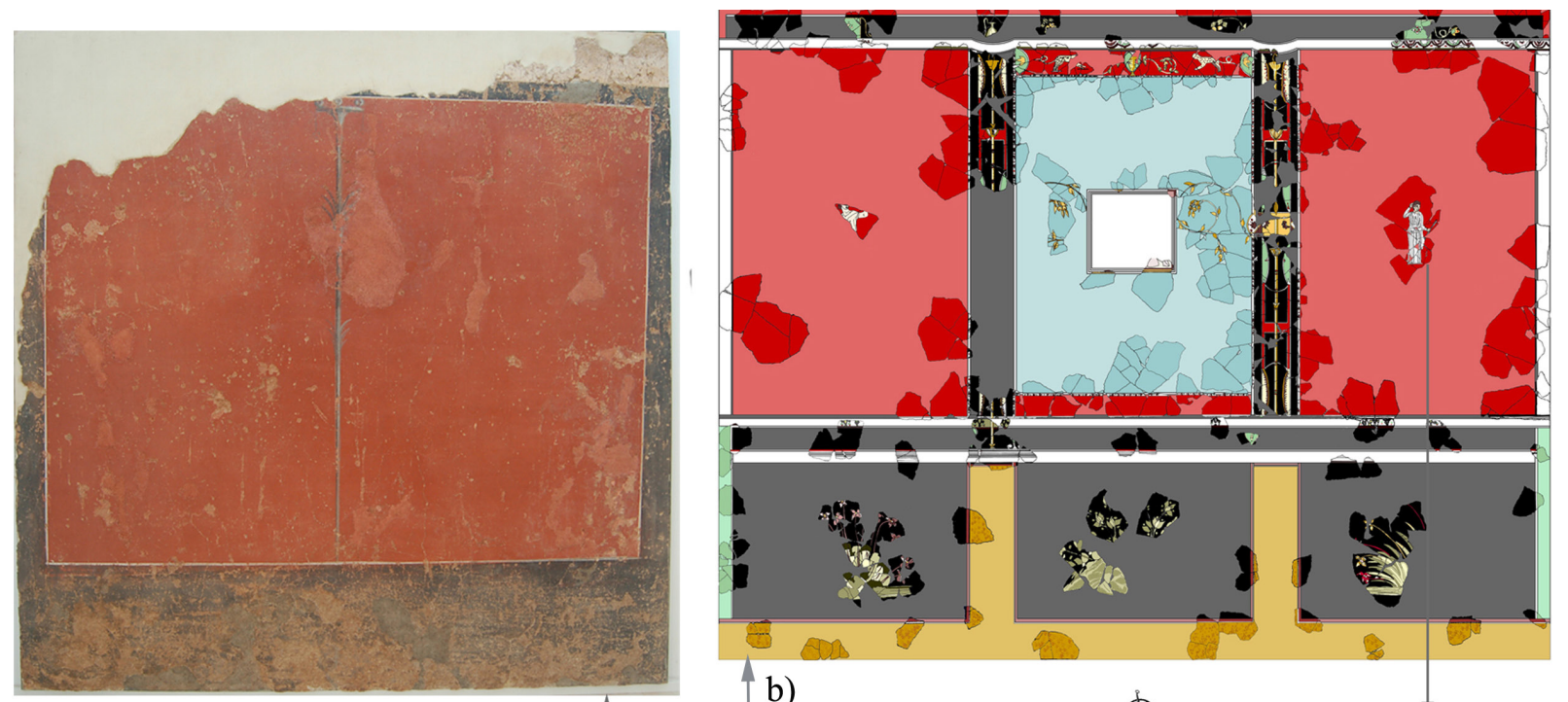

a)

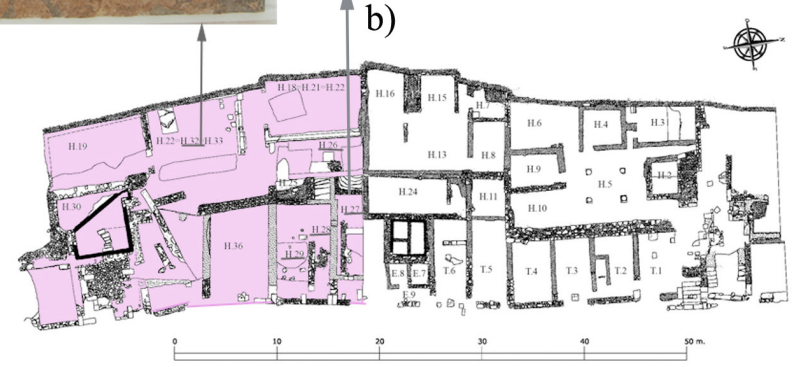

Fig. 4. Planta y restos pictóricos de la Domus 3 [Insula I] de Bilbilis: a) panel con representación de candelabro al revés [Bil. 4] (Museo de Calatayud) (fotog. de P. Uribe); b) conjunto recuperado en H. 27 [Bil. 3] (según J. Lope, L. Oronich y L. Íniguez).

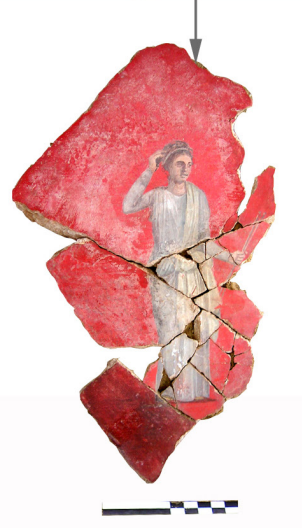

a veces adornados por trazos de encuadramiento con puntos en los ángulos y un fino moteado multicolor en el zócalo (Guiral y Martín-Bueno, 1996: 254-258); el conjunto del tablinum de la Domus 1 (Bil. 2) (Fig. 3a y b), basado en un zócalo moteado seguido de una sucesión de paneles rojos alternos con bandas; el revestimiento blanco del balneum de la misma vivienda [Bil. 1]; y las pinturas del conjunto hallado entre el espacio porticado [H . 3] y la estancia H. 18 de la Domus 3 [Insula I] [Bil. 4] (Fig. $4 a)$, donde un exiguo candelabro metálico es el único elemento decorativo sobre un panel con monocromía roja, seguido de una zona inferior negra.

Del periodo augústeo también son las decoraciones procedentes de Osca. En los dos conjuntos hallados en la posible casa excavada en la c/ Dormer 8-10 [Osc. 1 y 2] (Fig. 5a y b), observamos finos moteados multicolores para la zona inferior y paneles rojos en la zona media -quizá decorados por pequeños cuadritos centrales- separados entre sí por bandas negras. En el conjunto exhumado en la c/ Ainsa 14-16 angular a la calle Ricafort 2 [Osc. 3] (Fig. 5c), lo más destacado es la presencia de candelabros vegetales en bandas de fondo oscuro, que alternan con paneles planos de diferentes colores encuadrados interiormente por filetes de color beis.

Las pinturas analizadas en la Casa C o Domus de los Delfines de Celsa, debemos situarlas en un momento un poco posterior, en torno a los ańos 20-25 d. C., donde encontramos tanto banales monocromías para estancias secundarias -habitaciones 15a, 16 y 19 [Cel. 12, 14 y 15] (Mostalac y Beltrán, 1994: 117-118) - como decoraciones más significativas destinadas a las estancias de representación; en el tablinum [6] [Cel. 4] (Mostalac y Beltrán, 1994: 84) conocemos uno de los paneles planos de 

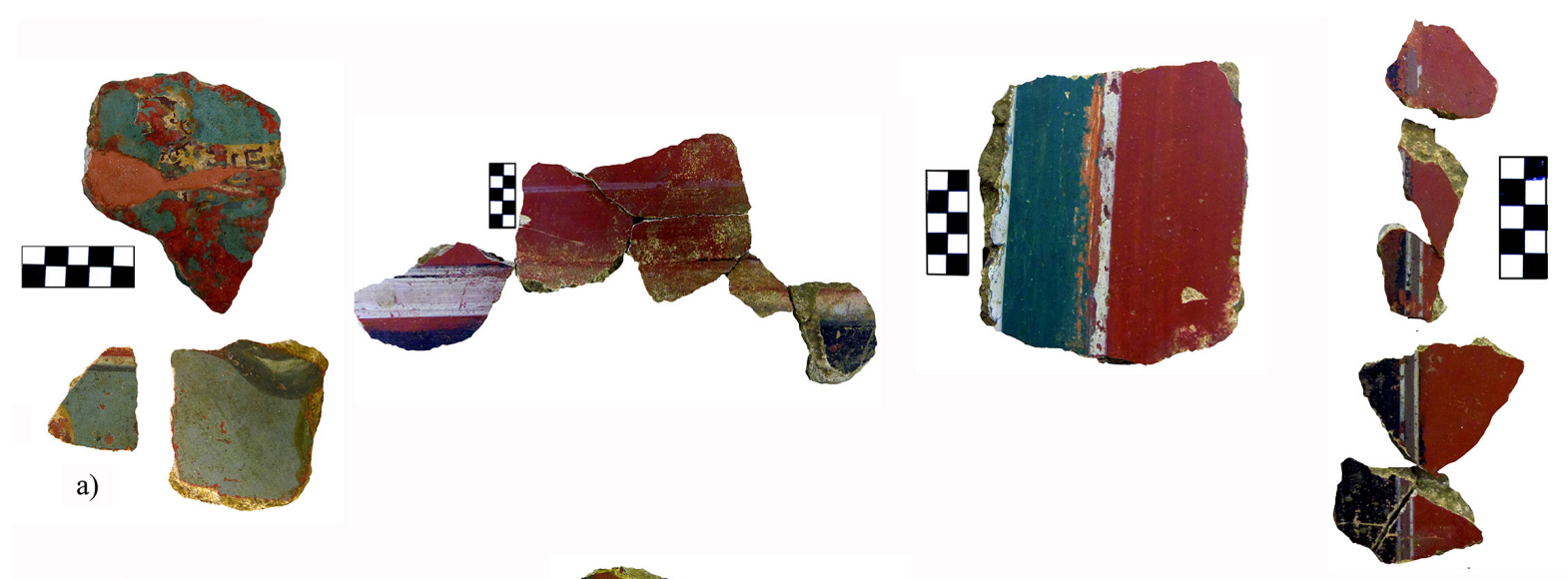

b)
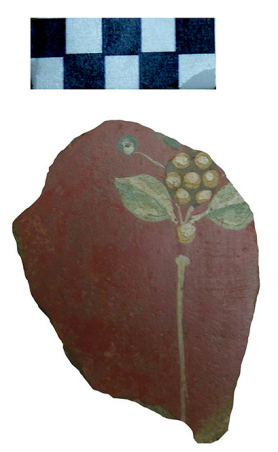

c)

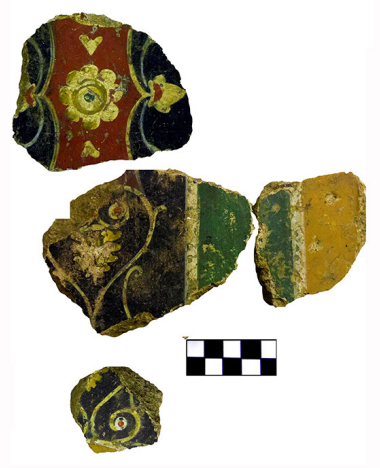

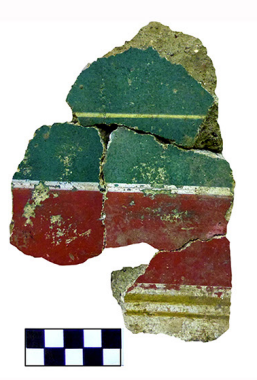

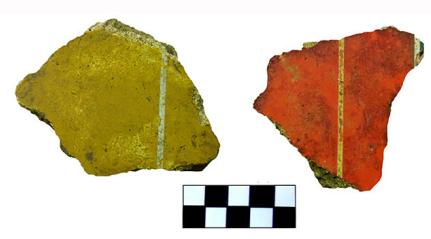

Fig. 5. Restos pictóricos: a) conjunto Osc. 1 hallado en la c/ Dormer; b) conjunto Osc. 2 hallado en la c/ Dormer; c) conjunto Osc. 3 hallado en la cl Ainsa-Ricafort.

la zona media, de color negro, y una curiosa zona superior con una banda en la que observamos una sucesión de triángulos. En el llamado oecus triclinar [12] [Cel. 10] (Fig. 6) (Mostalac y Beltrán, 1994: 87-117) se halló un magnífico techo que dividía la estancia en $2 / 3$ para la antecámara, ornado con un sistema de relación continua basado en casetones, y $1 / 3$ destinado a la cámara, con un sistema compositivo diferente, fundamentado en el cruce de diagonales. En ambos casos magníficos emblemas con variados personajes interrumpían dichas composiciones geométricas. En menor medida, también aportaron datos las pinturas halladas en la exedra [14] [Cel. 11] (Mostalac y Beltrán, 1994: 117) y en la estancia 7 [Cel. 7] (Mostalac y Beltrán, 1994: 86-87), donde se documentaron zócalos salpicados con un fino moteado.

En los años 35-45 d. C., fase tardía del in Estilo, nuevamente hemos de volver la mirada al yacimiento bilbilitano. En este momento se pintan distintas estancias de la Insula I. Destaca el magnífico conjunto hallado formando parte del relleno de una de las estancias [H. 27] de la Domus 3 [Bil. 3] (Fig. 4b) (Íñiguez, 2015). Este cuenta con imitaciones marmóreas de giallo antico y macizos vegetales en el zócalo, paneles decorados por musas, pequeños cuadritos y animales, e interpaneles ornados con candelabros vegetalizados y metálicos, así como una zona superior en la que se dispone el típico repertorio ornamental caligráfico del iII Estilo. De la misma cronología son los fragmentos hallados en las estancias [E. 7 y 9] del edificio CIv [Bil. 12] (Íñiguez et al., 2011). Remiten también a una rica decoración de la que suponemos que se articulaba en paneles rojos -decorado uno de ellos por un paisaje idílico-sacro- e interpaneles ornados por candelabros con sombrillas de las que colgaban o sobre las que se disponían seres mitológicos y animales. 

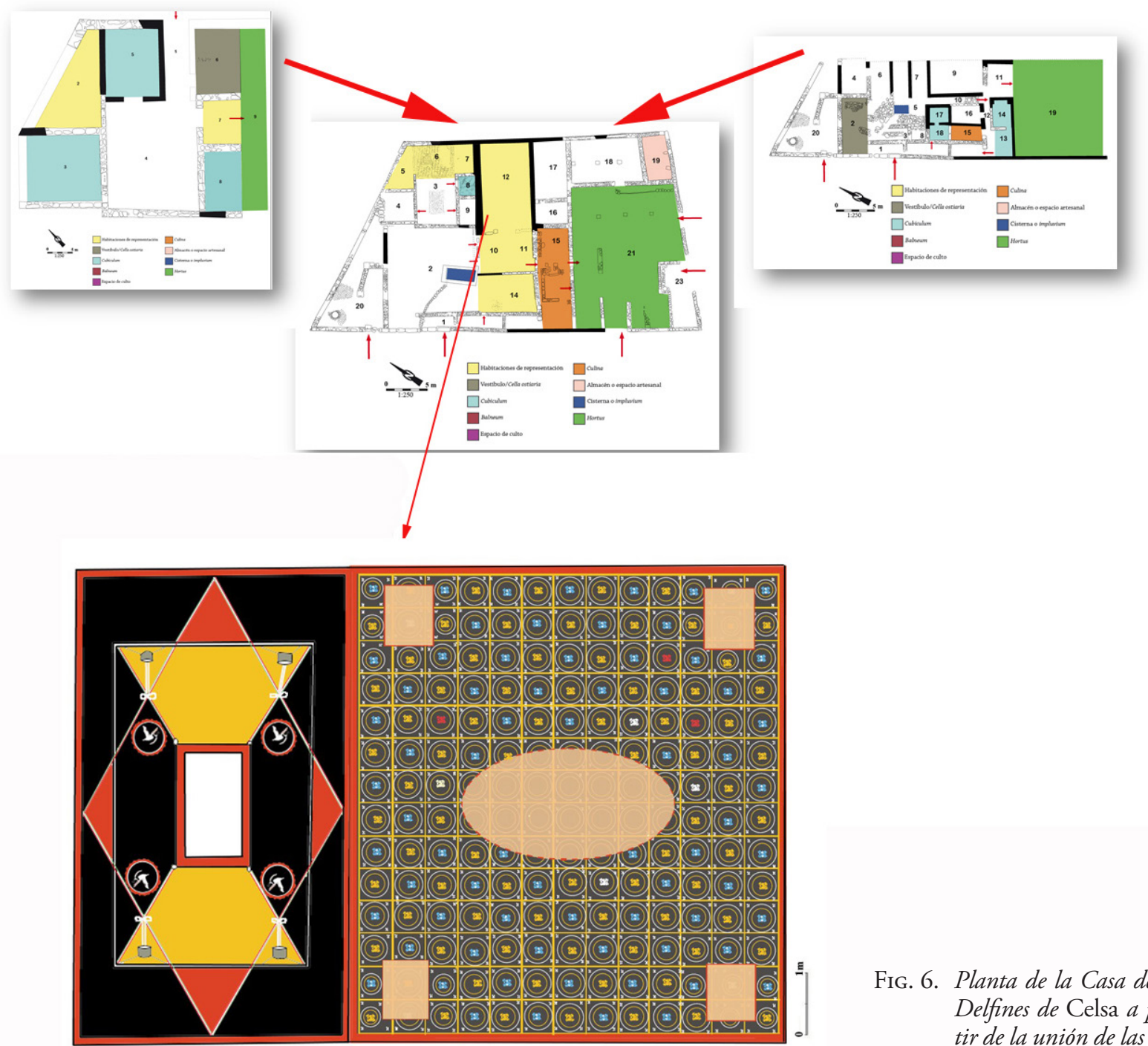
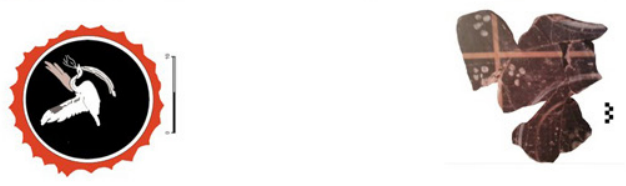

A finales de la primera mitad del s. I d. C., en el ocaso del periodo estilístico que ahora nos ocupa, debemos situar los fragmentos correspondientes a tres de los cuatro conjuntos de la vivienda de Labitolosa anterior a la hoy conocida como Domus 1 [Lab. 1, 3 y 4] (Fincker et al., 2013: 320-328). Presentan zonas inferiores cuyo moteado no es tan fino como en los primeros tiempos de la Era, ni tan grueso como el característico de la segunda mitad

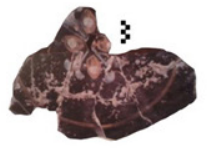

\section{Fig. 6. Planta de la Casa de los Delfines de Celsa a par- tir de la unión de las $\mathrm{Ca}$ - sas $A$ y $B$ y decoración pic- tórica del techo del oecus [12] [Cel. 10] (a partir de Mostalac y Beltrán, 1994).}

del s. I d. C. La zona media, conservada en las dos últimas pinturas citadas, presenta sobrios paneles planos de distintos colores, encuadrados por un filete amarillo. En el caso del conjunto Lab. 3, también encontramos filetes triples; y para el conjunto Lab. 4 , estos son sustituidos por filetes simples blancos con puntos en diagonal en los ángulos.

Antes de comenzar a enumerar los conjuntos correspondientes a la segunda mitad del s. I d. C., 
clasificables dentro del IV Estilo, es necesario traer a colación aquellas decoraciones pertenecientes al s. I d. C., pero cuya inclusión dentro del in Estilo pompeyano es más dudosa que en los casos anteriores. En primer lugar, debemos citar los exiguos fragmentos ornamentados con estrechos filetes triples recuperados en superficie en el entorno de la Casa del Peristilo de Los Bañales [Bañ. 2], cuya pertenencia a la primera mitad a juzgar por las características de este elemento decorativo supondría adelantar la fecha de construcción de la citada vivienda. En segundo lugar, la datación directa que nos ofrece la excavación del peristilo de la Domus 4 de Ercavica sólo nos indica la pertenencia de la decoración hallada en el pretil [Erc. 1] (Rubio y Valero, 2007: 439) al s. I d. C. La placa decorativa presenta un moteado que, como en el caso de Labitolosa, es intermedio, de tal forma que, a modo de hipótesis, quizá pudiera fecharse también a finales de la primera mitad del s. I d. C.

La entrada del iv Estilo en el conventus Caesaraugustanus se produce igualmente sin ningún tipo de retraso cronológico, hacia la mitad de s. I d. C. Como hemos visto para el III Estilo, también en esta etapa nos resulta complicado subdividir las

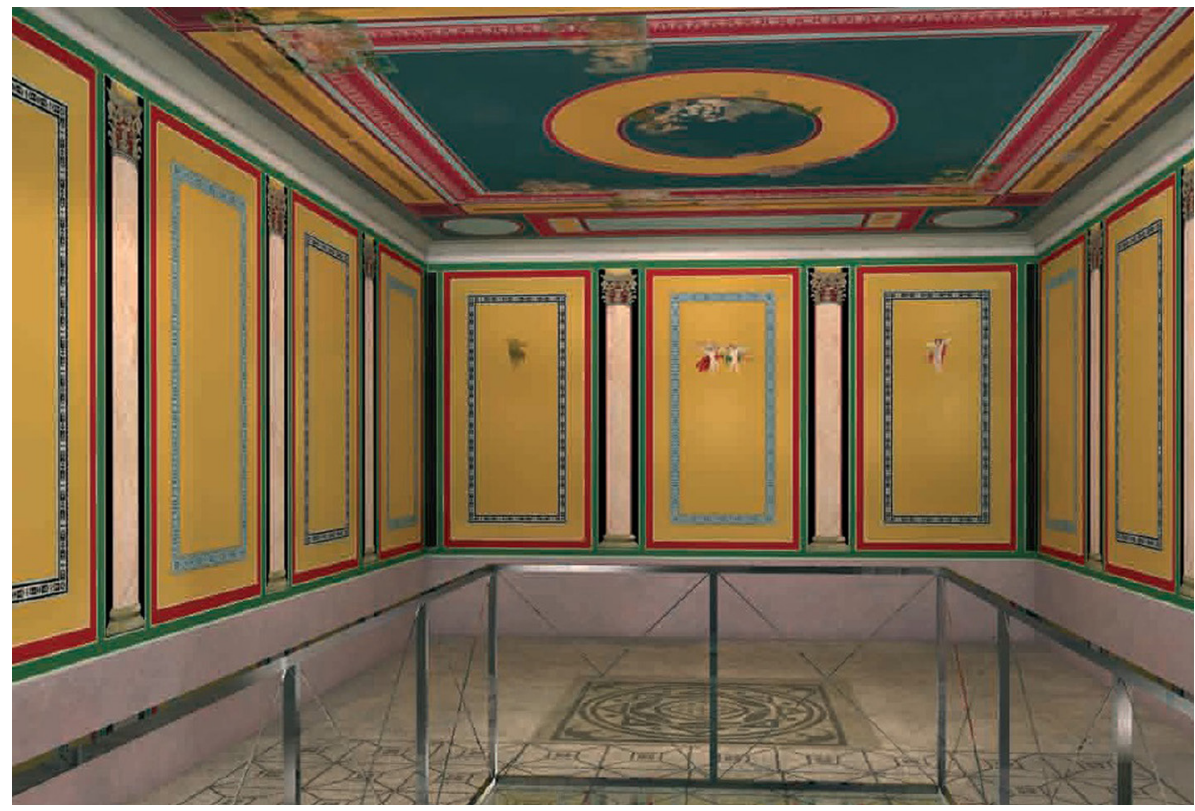

FIG. 7. Reconstrucción virtual de la decoración musiva y pictórica del triclinium de la cl Añón de Zaragoza [Caes. 1 y 2] (Mostalac et al., 2007). decoraciones que fechamos en este periodo en las dos fases establecidas para la península itálica: la primera hasta el fin de Pompeya y el incendio de Roma durante el reinado de Nerón -62/64 d. C.y la segunda hasta la llegada de la dinastía flavia (Barbet, 1985: 183-192). En nuestro caso, consideramos que las pinturas incluidas dentro del IV Estilo se clasifican en las realizadas en los primeros decenios de la segunda mitad del s. I d. C. y las elaboradas en época flavia, es decir, en esa tercera etapa a la que se refirieron de forma pionera autores como K. Schefold (1953-54).

A un Iv Estilo precoz pertenece el techo perteneciente al triclinio hallado en la c/ Añón [Caes. 2] (Fig. 7) (Mostalac et al., 2007), de Caesar Augusta -habitación que cuenta con dos fases decorativas-. Se organiza en una forma geométrica cerrada articulada en una serie de bandas concéntricas que finalizan en un cuadrado en el cual se inscribe un círculo con una escena mitológica. El único conjunto de la vivienda anterior a la Domus 1 de Labitolosa que no hemos citado anteriormente también se fecharía en los primeros años de la segunda mitad del s. I d. C. [Lab. 2]. Cuenta con un zócalo en cuyo moteado se aprecian ya manchas, y una zona media basada en la sucesión de paneles rojos encuadrados por filetes blancos, y separados por bandas negras.

El Iv Estilo canónico se encuentra amplia y ricamente desarrollado en Bilbilis. Resultan representativas a este respecto las decoraciones presentes en tres de los cuatro conjuntos hallados en las termas [Bil. 19, 20 y 21] (Fig. 8a y b). El conjunto Bil. 19 presenta grandes paneles azules intercalados con interpaneles de fondo blanco decorados con candelabros coronados por cisnes y figuras 
a)

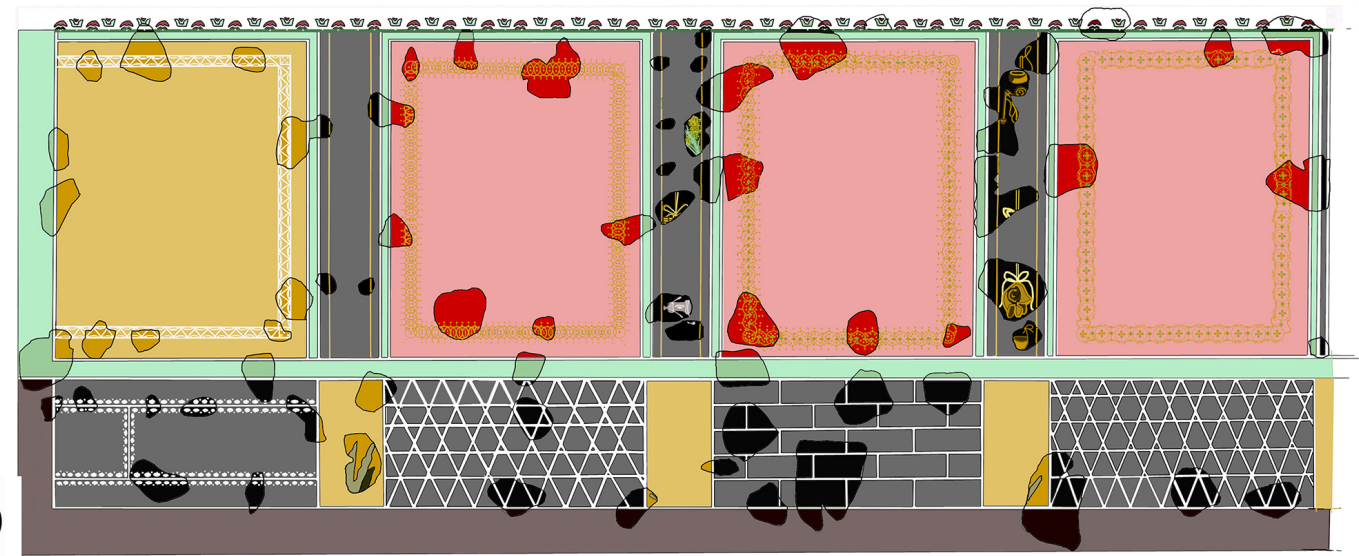

b)

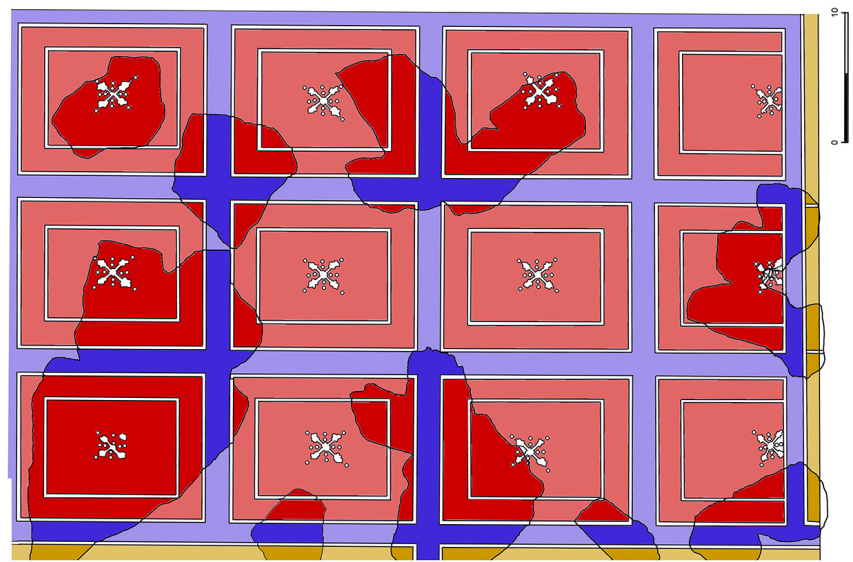

c)

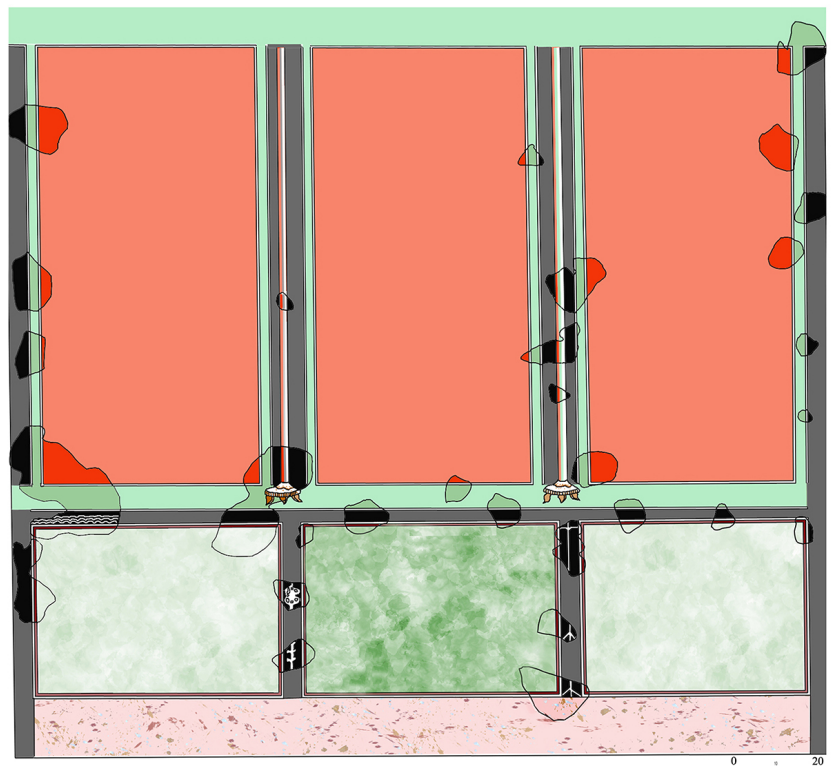

Fig. 8. Conjuntos Bil. 20-22 procedentes de las termas de Bilbilis (según Guiral y Martín-Bueno, 1996). 

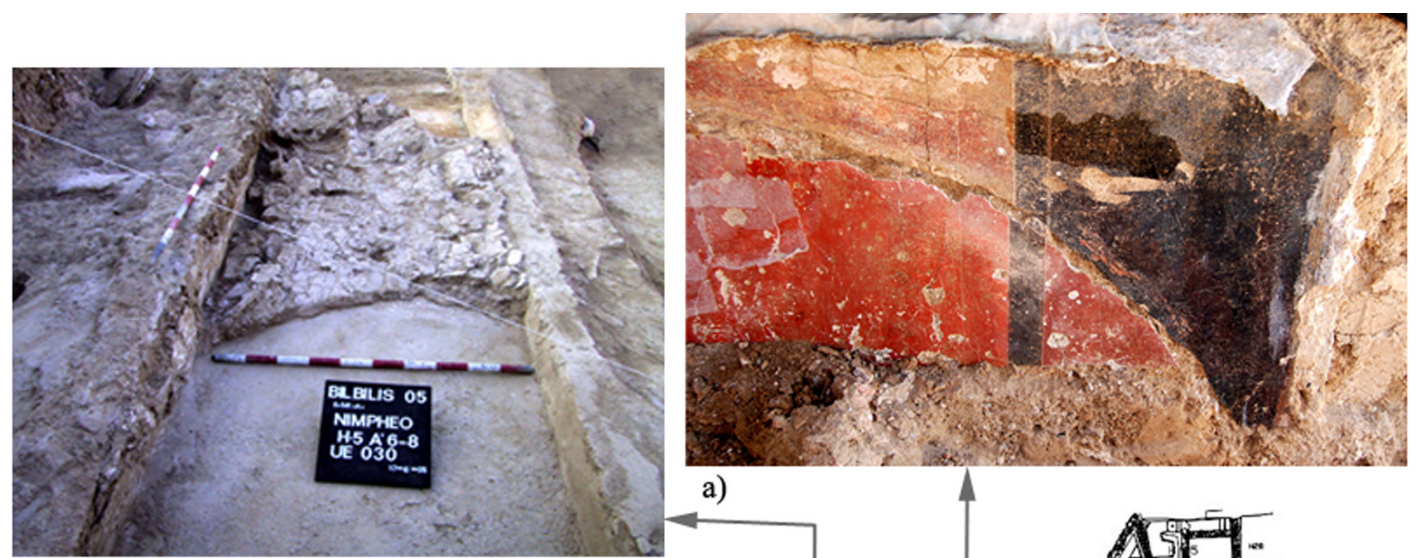

b)

a)

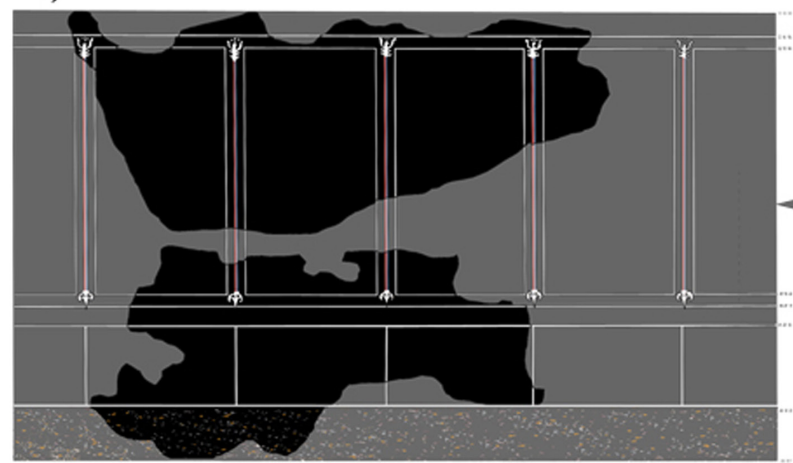

c)
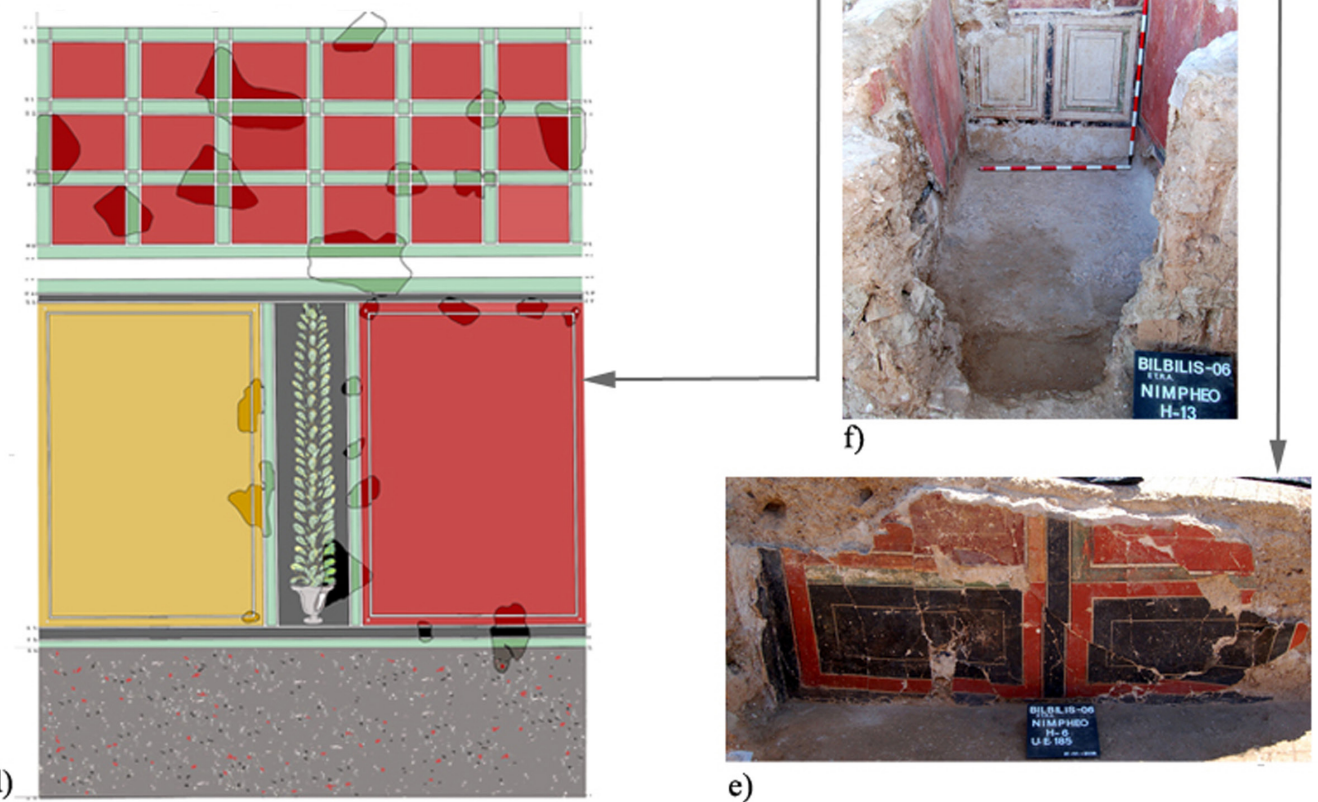

e)

Fig. 9. Planta y restos pictóricos de la Casa del Larario de Bilbilis: a) repinte documentado en el ángulo sureste del tablinum (Archivo excavación de Bilbilis); b) caída de la bóveda del pasillo (H. 5) (Bil. 7) (Archivo excavación de Bilbilis); c) restitución de la decoración del triclinium (H.4) (Bil. 11) (a partir de Guiral y Martín-Bueno, 1996); d) restitución del conjunto Bil. 8 procedente de H. 1 (a partir de Guiral y Martín-Bueno, 1996); e) decoración del muro oriental del atrium (H. 6) (Bil. 5) (Archivo excavación de Bilbilis); f) sacrarium (H. 13) (Bil. 6) (Archivo excavación de Bilbilis). 
colgantes; también hay un zócalo con macizos vegetales que se alternan con imitaciones de aparejo isódomo y cenefas caladas. El conjunto Bil. 20 cuenta con un esquema compositivo similar. En este caso las cenefas caladas encuadran los paneles rojos y amarillos de la zona media. Objetos colgantes también se hallan en los interpaneles negros, mientras que en el zócalo, alternándose igualmente con macizos vegetales, encontramos el mismo aparejo isódomo, cenefas caladas y figuras geométricas. Por último, el conjunto Bil. 21 nos remite una zona superior y un techo, organizados en casetones rojos separados por bandas azules (Guiral y Martín-Bueno, 1996: 96-134).

En la Casa del Larario de Bilbilis, el rv Estilo se halla ampliamente representado. Encontramos un conjunto procedente del atrio [H. 6] [Bil. 5] (Fig. $9 \mathrm{e})$, con una decoración basada en bandas y figuras geométricas en el zócalo; también el conjunto que decoraba el magnífico sacrarium (H. 13) (Bil. 6) (Fig. 9f) (Sáenz y Martín-Bueno, 2010: 823826) concebido para que la atención no se centre en las paredes -decoradas con simples paneles rojos separados por bandas verdes- sino en la aedicula que se orna con un grupo de figuras mitológicas y personajes finamente realizados en estuco. Quizá a este periodo también pertenezca el enlucido blanco del pasillo [H. 5] [Bil. 7] (Fig. 9b). En el conjunto hallado en la estancia [H. 1] [Bil. 8] (Fig. 9d), probablemente procedente de la segunda planta, observamos una zona superior similar a la presente en el conjunto de las termas. En la zona media, lo más destacado es el candelabro vegetal dispuesto entre paneles de diferentes colores encuadrados por filetes blancos con puntos en los ángulos (Guiral y Martín-Bueno, 1996: 349-356). También conocemos el zócalo, moteado en este caso con manchas. Muy interesante es el triclinium (H. 4) [Bil. 11] (Fig. 9c) (Guiral y Martín-Bueno, 1996: 364-372), con una total monocromía negra sólo interrumpida por unos curiosos y finos candelabros tipo tirso. Por último, no debemos olvidar que es en este momento cuando se lleva a cabo la reforma del tablinum, que se decoró en época republicana, donde se aprecia que los pintores, que reproducen la anterior decoración, han olvidado totalmente la misión real de los filetes bícromos -sustituidos ahora por simples filetes blancos- que encuadraban la zona media, pues no los utilizan para simular el relieve de los ortostatos, algo representativo del ir Estilo, pero que se pasó por alto en la reforma (Fig. 9a).

En la Casa de las Escaleras, uno de los tres conjuntos hallados [Bil. 14] presenta una decoración banal basada en paneles planos rojos encuadrados por filetes amarillos y separados entre sí por bandas negras y verdes (Guiral y Martín-Bueno, 1996: 248254). Están precedidos de un zócalo cuyo moteado se realizó con gotas y manchas. Del conjunto Bil. 16 solo ha llegado hasta nosotros el zócalo similar al que acabamos de describir (Guiral y Martín-Bueno, 1996: 258). Por otro lado, el único conjunto hallado en la Casa de la Cisterna (Bil. 13) (Guiral y Martín-Bueno, 1996: 315-346) cuenta con las características cenefas caladas en la zona media, que recorren paneles rojos y amarillos separados entre sí por bandas verdes y blancas. Curioso es su zócalo con bandas en diagonal.

Cinco conjuntos (Arc. 1, 2, 3, 4 y 5) pertenecientes al periodo cronológico que nos ocupa fueron diferenciados a partir de los fragmentos exhumados en las distintas habitaciones de la Casa del Pretorio de Arcobriga (Fig. 10) y también se adscriben al Iv Estilo (Guiral, 1991; Guiral y Mostalac, 1992). Presenta ornamentos canónicos del citado periodo, como las cenefas caladas presentes en los conjuntos Arc. 1 y 5 . Del conjunto Arc. 2, únicamente han llegado hasta nosotros fragmentos pertenecientes a un zócalo decorado con una imitación de aparejo isódomo y con figuras geométricas. Otro de los conjuntos [Arc. 3] presenta un personaje masculino posiblemente enmarcado en un cuadrito. Por último, las piezas del conjunto Arc. 4, donde observamos un delfín y guirnaldas, corresponden quizá a un techo.

En la Casa del Peristilo de Los Bañales, además del conjunto hallado en superficie citado más arriba [Bañ. 2] se exhumó otro [Bañ. 1] -posiblemente perteneciente a esta primera parte de la segunda mitad del s. I d. C.- durante la excavación de un posible $c u$ biculum (Uribe et al., 2011:246-253), que se articula en un zócalo moteado con gotas y manchas, seguido de una zona media en la que se suceden paneles de distintos colores separados por filetes. 
Antes de pasar a las pinturas fechadas en el periodo flavio, debemos traer a colación el segundo de los conjuntos exhumado en la Domus 4 de Ercavica [Erc. 2]. Fue hallado en una de las estancias cercanas al peristilo; presenta un doble filete vertical sobre fondo rojo y sin relleno, que parece remitir a los típicos elementos decorativos que acompañaban a las cenefas caladas en la etapa que nos ocupa. Sin embargo, a juzgar por los datos proporcionados por los niveles estratigráficos excavados, pertenece a época republicana (Rubio y Valero, 2007: 440).

Las decoraciones del conventus Caesaraugustanus fechadas en época flavia sin duda se diferencian claramente de las anteriores. Así lo constatamos en las paredes del triclinium de la c/ Añón [Caes. 1] (Fig. 7) de Caesar Augusta (Mostalac et al., 2007: 255-261), con paneles decorados con pequeñas figuras -realizadas de forma impresionista- y orlas caladas opacas, y separados entre sí por columnas planas sin función arquitectónica. En la misma ciudad, un conjunto hallado in situ en el zócalo de una de las estancias de la posible domus exhumada en la c/ Palomeque [Caes. 6] y otro perteneciente a otra posible vivienda de época flavia hallada en la Avda. de César Augusto [Caes. 9] nos muestran fragmentos moteados sobre fondo claro realizados de forma mucho más burda que en periodos anteriores. Un lararium tipo aediculum, con nicho absidial, cúpula gallonada y podium decorado con imitaciones marmóreas, procedente también de la casa excavada en la c/ Palomeque [Caes. 5], igualmente ha sido adscrito a este periodo (Mostalac y Guiral, 1987: 189-191). Por otro lado, verificamos que se sigue recurriendo a soluciones pictóricas funcionales para estancias secundarias. Así lo documentamos en la vivienda exhumada en la c/ Predicadores [Caes. 7] donde, además de un zócalo blanco in situ limitado por una banda roja, hallamos un fragmento que remite al denominado zocollo sporgente.

Otro lararium, hallado en este caso in situ en la Casa de la Fortuna de Bilbilis [Bil. 17] se fechó en etapa flavia (Guiral y Martín-Bueno, 1996: 235-244) debido, fundamentalmente, a la información proporcionada por los niveles estratigráficos, ya que la pintura tan solo muestra el cuerpo de la diosa que dio nombre a la vivienda.
Hemos de añadir este bloque cronológico la decoración, basada en un moteado con gruesas manchas, del pretil de la Casa de L'Antic Portal de Magdalena [Ile. 1] (Fig. 11). Por último, incluimos las pinturas procedentes de la Domus 1 de Labitolosa, las presentes en la habitación 1, un techo y unas paredes totalmente enlucidos de blanco [Lab. 5]; y los fragmentos exhumados en la habitación 4 correspondientes a un zócalo blanco moteado con gruesas manchas y una zona media articulada en paneles amarillos separados por bandas rojas [Lab. 6] (Fincker et al., 2013: 316-319).

\subsection{Repertorio ornamental y esquemas compositivos del III Estilo en el conventus Caesaraugustanus}

La llegada de Augusto al territorio, como ya hemos apuntado, supone un cambio. Es la época en la que en muchos de los yacimientos estudiados se proyectan los grandes edificios públicos, pero también algunos privados, y en ellos comprobamos que una nueva moda decorativa invade los distintos ambientes de los mismos.

En cuanto a los esquemas compositivos estudiados son tres los constatados. En primer lugar, una sucesión de paneles lisos de diferentes colores. Se trata de la organización decorativa más simple, que hallamos en Bilbilis, en los conjuntos Bil. 10 y Bil. 15, y posiblemente en el conjunto Lab. 3 . En ellos, cobran especial protagonismo los filetes simples, dobles o triples que encuadran los paneles o actúan como elemento de separación de los mismos, si bien a veces este papel lo ejecuta una estrecha banda. En segundo lugar, una alternancia de paneles con anchas bandas o interpaneles ornados con candelabros. Es la más popular pues la hallamos en la mayoría de los conjuntos de este periodo. Sin embargo, debemos establecer una pequeña subdivisión: mientras que en los conjuntos Caes. 7, Bil. 2, Osc. 1, Cel. 4, y Lab. 4, son simples bandas sin -o con escasa- decoración, las que separan -y a veces encuadran, como en el último caso- los paneles medios; en los conjuntos Bil. 3, 12 y 22, y Osc. 3, son los candelabros - a veces exiguos, como en el primer conjunto, y otras veces profusamente desarrollados, 
como en las otras tres decoraciones- los que adquieren gran protagonismo en la composición, dentro de los interpaneles. En tercer lugar, decoraciones con fondo de color uniforme pero con elementos verticales que se presentan compartimentando el espacio. Por el momento, únicamente se constata en Bilbilis, en los conjuntos Bil. 4 y 9.

Hemos de referirnos también a los dos únicos techos fechados en este periodo, cuyo estado de conservación permite acercarnos a sus diferentes esquemas compositivos: sistema de relación continua basado en la sucesión de una serie de casetones pintados. Se halla presente en el tramo abovedado del techo de la estancia 12 de la Casa de los Delfines de Celsa (Cel. 10); sistema libre basado en el cruce de diagonales, el cual también se encuentra en la misma cubierta traída a colación para el punto anterior, pero en el tramo plano; y sistema basado en bandas concéntricas encajadas unas dentro de otras hasta llegar a una figura geométrica central. Lo constatamos en el techo del triclinium hallado en la c/ Añón de Zaragoza (Caes. 2) ${ }^{8}$.

En el repertorio ornamental del III Estilo encontramos una amplia gama de motivos. Abordaremos a continuación las distintas zonas en que tradicionalmente se dividió la pared romana comenzando por el zócalo.

El elemento más utilizado en esta sección es el moteado fino multicolor sobre fondo negro [Cel. 7 y 13, Bil. 2, 9 y 15, Osc. 1 y Lab. 3], aunque también lo hallamos sobre fondo gris o rosa [Cel. 11, Caes. 4 y 8, el rodapié de Bil. 22 y Lab. 4]. Destacan, por su rareza en el territorio que nos ocupa, los zócalos que ejecutan el moteado sobre un fondo rojo [Lab. 1 y Erc. 1]. Tras el análisis de todos ellos podemos decir que la técnica de realización del moteado la podemos tomar como uno de los marcadores que nos pueden ayudar a acotar la cronología de los conjuntos pictóricos pertenecientes al s. I d. C., ya que en la primera mitad de esta centuria el moteado se realiza con una fina llovizna -de tal forma que presenta gran similitud con las

${ }^{8}$ Recordemos que se trata de un conjunto correspondiente al Iv Estilo precoz. La mayoría de elementos que presenta se pueden encuadrar todavía dentro del III Estilo o en una fase de transición. piedras graníticas a las que pretende imitar- mientras que en la segunda mitad, como luego veremos, las gotas son más gruesas y burdas -perdiendo así toda intención de emular modelos reales, quedando como un mero recurso decorativo-. En cuanto al color de la superficie sobre el cual se disponen las motas y gotas, es cierto que hay un predominio de fondos negros en la primera mitad y de fondos claros en la segunda, aunque la presencia de unos y otros durante todo el siglo que nos ocupa hace que no debamos tomar este criterio como un aspecto inamovible (Guiral et al., 1986).

También hallamos zócalos en los que se recurre a la imitación de mármol. Nuevamente, es el yacimiento bilbilitano donde lo encontramos: en el conjunto Bil. 22, se emulan mármoles verdosos, sin que haya sido posible la identificación concreta de la variedad; en el conjunto Bil. 3, sin embargo, sí que se ha podido constatar que es el mármol numídico o giallo antico el tipo concreto que se ha querido representar.

El tercer elemento decorativo documentado han sido los macizos vegetales, presentes también en los paneles del zócalo del conjunto Bil. 3, combinándose con las imitaciones de mármol existentes en los interpaneles. También cabe destacar aquí los curiosos elementos vegetales que decoran los interpaneles del conjunto Bil. 22.

En la transición hacia la zona media, hallamos un recurso muy característico del III Estilo, la imitación mediante filetes de distintos colores de una cornisa ficticia, en los conjuntos Bil. 3 y Osc. 1 y 3 . Este elemento decorativo, reminiscencia de los ornamentos arquitectónicos del II Estilo, será sustituido en la segunda mitad del s. I d. C. por una amplia banda verde, algo que podemos ver en algunos de nuestros conjuntos (Bil. 9, 10 y 22).

El repertorio ornamental de la zona media hay que dividirlo en dos grupos, dependiendo de si nos referimos a las superficies planas de los paneles medios o a los elementos que actúan de separación de los mismos -normalmente en el interior los interpaneles o bandas- $\mathrm{o}$ articulándolos.

Comenzando por este segundo grupo, hemos observado que uno de los elementos más comunes dentro de los interpaneles o articulando los paneles 
medios son los candelabros ${ }^{9}$. Se han documentado conjuntos que muestran candelabros que imitan modelos metálicos -cuyas basas son de los tipos à roulettes $^{10}$ [Bil. 4] y de garra de animal [Bil. 22]pinturas en los que estos elementos se presentan de forma más vegetalizada -con elementos fusiformes y sobrillas a lo largo de su fuste [Bil. 12] o tan desarrollados u originales que apenas podemos identificarlos con el elemento que les da nombre [Caes. 3 y Osc. 3]- y otras decoraciones en las que se muestran de manera combinada tanto candelabros metálicos como vegetales [Bil. 3]. No podemos considerar como tal, aunque sí debemos tenerlo en cuenta, el fino elemento vegetal decorado con elementos bifolios, presente en una de las bandas de separación del conjunto Bil. 2.

El segundo elemento a considerar dentro de este grupo son las columnas, acanaladas y decoradas con elementos vegetales, que articulan los paneles medios del conjunto bilbilitano Bil. 9. Bien es cierto que dada la ausencia de la zona superior no podemos saber si estas columnas sustentaban una estructura arquitectónica. Si fuera así, no podríamos clasificarlos como interpaneles.

En cuanto al repertorio que orna los paneles medios propiamente dichos, hallamos varios elementos. Mayoritaria es la presencia de un recurso tan característico de este periodo como son los filetes dobles y triples (Bastet y De Vos, 1979: 135), a veces encuadrando interiormente dichos paneles [Caes. 8, Bil. 10 y Bañ. 2]. En dos ocasiones se combinan con filetes simples también de encuadramiento, de color blanco [Osc. 1 y Bil. 2] o amarillo [Lab. 3]. Otras

9 En el III Estilo, los elementos heredados de las arquitecturas del II Estilo sufren un importante cambio de ornamentación, y así las columnas, tan características del mismo, son sustituidas por una variadísima gama de candelabros. Sin embargo, ha sido uno de los ornamentos menos tratados hasta su sistematización tipológica por M. de Vos (1976: 59-64), dentro de un estudio global y un primer intento de catalogación de pintura pompeyana.

10 Se trata de un tipo de basa formada por tres pequeńas bolas; se denomina así en la bibliografía francesa, ya que se trata de una tipología documentada en muchos conjuntos de este territorio, por ejemplo, en la rue des Farges en Lyon (Barbet, 2008: fig. 57). veces, estos filetes simples aparecen como único elemento decorativo. A este respecto, cabe detenernos en aquellos trazos de este tipo pintados en amarillo -al caso labitolosano ya citado añadimos los conjuntos Lab. 4 y Bil. 12- pues no hacen su aparición hasta bien avanzada la primera mitad del s. I d. C. (Guiral y Martín-Bueno, 1996: 253), por lo que se trata de un elemento que también puede ser utilizado como marcador cronológico. Tiene su origen en los filetes bícromos que simulaban, con un juego de luz y sombra, los relieves de los ortostatos en el II Estilo. La misma explicación podemos proporcionar para la presencia en algunos conjuntos de uno [Bil. 12] o varios puntos [Bil. 15 y Lab. 4] en el ángulo formado por estos filetes, ya que también suponen una reminiscencia de dicho sombreado.

Otro de los elementos decorativos observados son los galones decorados con elementos cordiformes, que actúan de separación entre paneles e interpaneles. En las ciudades campanas se encuentran muy ligados al periodo que nos ocupa (Bastet y De Vos, 1979: 128), asociados además a conjuntos con gran riqueza ornamental, como ocurre en nuestro caso (Osc. 1 y Bil. 3). La predela -sin decoración-, reminiscencia del podium característico del II Estilo (Mostalac, 1996: 19), se ha documentado en el conjunto Bil. 3, aunque quizá también podemos considerar como tal la banda, en este caso adornada, presente en el conjunto Bil. 9. Personajes mitológicos -posiblemente algunos de ellos enmarcados en cuadritos centrales-, animales y elementos vegetales, realizados de forma caligráfica, poblaron los paneles [Osc. 1 y 2, y Bil. 3] e interpaneles [Bil. 12] de algunas de las decoraciones del conventus, claros ejemplos del repertorio miniaturista característico del III Estilo, comparables a los presentes en las principales viviendas campanas (Bastet y De Vos, 1979).

Ha llegado hasta nosotros un porcentaje mínimo de fragmentos o placas pertenecientes a la zona superior de la pared, por lo que no contamos con una verdadera muestra representativa de la ornamentación de esta sección. Dos son los principales elementos constatados. Por un lado, frisos de fondo blanco a imitación de cornisas molduradas con la presencia de forma esquemática de flores de loto 
invertidas [Bil. 12], combinadas en otro caso [Bil. $3]^{11}$ con palmetas ${ }^{12}$. Quizá también haya que situar en esta sección uno de los fragmentos con este elemento decorativo del conjunto Cel. 5. Por otro, están los frisos de fondo blanco con una sucesión de triángulos de los que sólo contamos con un único caso [Cel. 4].

El repertorio ornamental de los techos documentados en el III Estilo presenta dos características fundamentales. En primer lugar, constatamos pequeños ornamentos caligráficos -frutos, animalillos, flores de cinco puntos, personajes, etc.- que pueblan toda la superficie [Cel. 10 y Caes. 2, dos de los fragmentos de Cel. 5 y algunos de Bil. 6]. En segundo lugar, emblemas con personajes o escenas mitológicas encuadrados y situados en la parte central [Cel. 10, tramo abovedado y Caes. 2], y también de forma simétrica en los laterales [Cel. 10, tramo plano] de la composición. Es necesario recordar que las dos cubiertas conservadas en las que hallamos este tipo de imágenes corresponden a triclinios. En ellas se hace referencia al mundo dionisiaco, dios del vino, en clara consonancia con la funcionalidad de este tipo de estancias ${ }^{13}$. Llamativo es el caso del conjunto Cel. 10, pues, además de la escena vinculada a dicha divinidad presente en la parte plana del techo, encontramos en la parte abovedada un emblema con la representación de Venus. Así, una observación conjunta de la cubierta nos permite establecer el binomio vino-amor, una escena-dionisiaca, erótica e intelectual-alusiva al otium popularmente representado en pintura a partir de Claudio; esta temática

11 Este conjunto también presenta en la zona superior pequeñas jarritas que imitan modelos metálicos y hojas de vid, en la banda negra que sigue al friso descrito.

12 En las primeras fases del in Estilo, las cornisas pintadas horizontales, ubicadas en la zona de transición entre el zócalo y la zona media o entre esta y la superior, pierden el carácter de cima recta y/o reversa, desapareciendo sucesivamente su carácter arquitectónico para ser sustituidas por frisos con flores estilizadas. Bastet y De Vos (1979: 135), bajo el epígrafe bordo a motivi floreali estilizzati, recogen, entre otros autores, la práctica totalidad de los ejemplos del III Estilo.

13 Ling (1995: 250) reconoció la popularidad de esta temática en los ambientes interpretados como triclinia. vino a sustituir a los cuadros y emblemas de carácter heroico y moralizante característicos de la época augústea (Romizzi, 2006: 138-145).

Podemos concluir que el III Estilo en el conventus Caesaraugustanus presenta esquemas compositivos estándar que cuentan con un repertorio ornamental que gana en calidad y detallismo a partir del segundo cuarto del s. I d. C. Destaca, sobre todo, por estar plenamente influenciado por las modas itálicas más en boga en ese momento. Se corrobora así que el territorio no sufre retraso cronológico alguno respecto a la metrópoli.

\subsection{Esquemas compositivos y repertorio ornamental del IV Estilo en el conventus Caesaraugustanus}

Los conjuntos fechados en la segunda mitad del s. I d. C. no difieren en exceso de lo constatado para el III Estilo, en lo que respecta al sistema compositivo. Hallamos fundamentalmente dos esquemas. En primer lugar, una sucesión de paneles en los que estrechas bandas o filetes dobles actúan de separación. La particularidad de este periodo es que se añade una banda verde ${ }^{14}$ entre los dos primeros elementos, a veces encuadrando el conjunto [Bil. 5, 6, 13 y 14], aunque no ocurre en todos los casos [Bañ. 1, Lab. 2 y 6]. Y, en segundo lugar, una alternancia de paneles anchos y estrechos decorados por candelabros [Bil. 8, 11 y 19 y Arc. 1, 2 y 5], objetos colgantes [Bil. 19 y 20] o columnas [Caes. 1]. También en este esquema, en la mayoría de los casos, se añaden bandas verdes entre paneles e interpaneles, aunque en los conjuntos Bil. 19 y Arc. 2 esta banda es roja.

Si nos referimos ahora a los techos estudiados pertenecientes al Iv Estilo, aunque hemos constatado la existencia de varios, tan sólo en uno de ellos hemos podido documentar el sistema compositivo. Se trata de un sistema en relación continua basado en la sucesión de casetones pintados. Es el que presenta el conjunto Bil. 21, muy relacionado con la zona superior del conjunto Bil. 8.

En cuanto al repertorio ornamental y como en el apartado anterior, comenzaremos la descripción

14 Tan sólo el conjunto Bil. 2 presentaba estas bandas verdes ya en el periodo anterior. 
por el zócalo. De nuevo en la mayoría de conjuntos se recurre al moteado, aunque ya no habrá en este periodo un deseo por imitar una piedra real, sino que las anteriores motas multicolores, convertidas ahora en gotas y manchas sobre un fondo uniforme, dan como resultado un elemento decorativo utilizado como mero recurso que para nada emula - ni desea hacerlo- una roca (Guiral et al., 1986: 277278). Lo cierto es que apenas contamos con moteados realizados sobre fondo negro - mayoritario en el iII Estilo-. Sólo podemos citar a este respecto el rodapié del conjunto Bil. 11 -donde este color viene impuesto por la monocromía negra presente en las tres secciones de la pared y en el techo- y una de las zonas del pretil del conjunto ilerdense Ile. 1. La mayoría de moteados de Iv Estilo se realizan sobre fondos grises o rosas [Lab. 2, Bil. 6, 8, 14 y 16]. Sí podemos apuntar que hay cierta tendencia a los moteados sobre fondo amarillo o blanco [Ile. 1, Lab. 6, Caes. 6 y 9], en los conjuntos que se fechan hacia finales del s. I d. C., donde además las manchas efectuadas sin ninguna dirección concreta suelen ser de un único color ${ }^{15}$. También en este periodo continúan las imitaciones marmóreas en esta zona de la pared. A veces identificamos el tipo de mármol representado [Caes. 5, donde se imita giallo antico], siendo este hecho imposible en otras ocasiones [Caes. 1].

A estos motivos se suman figuras geométricas sobre fondo negro, imitando un aparejo isódomo se han documentado en los conjuntos Bil. 19, 20 y Arc. 3. En los dos últimos además, se presentan también otro tipo de figuras geométricas sobre el mismo fondo, formadas por el cruce de líneas en diagonal que producen espacios cuadrados o triangulares a modo de cancella. También contamos con varios tipos de cenefas caladas, elemento novedoso de este periodo: las formadas por un filete bordeado por motivos en forma de gotas de agua [Bil. $19 \mathrm{y}$

15 Belot (1986: 12-13), sin negar la perduración a lo largo de toda la historia de la pintura mural romana de este elemento, constata la popularidad del moteado a base de manchas realizado con un solo color sobre fondo amarillo o blanco, a partir de finales del s. I d. C. y sobre todo en el s. II d. C.
20 y Arc. 2] y las compuestas por una sucesión de cuadriláteros o de triángulos [Bil. 19].

Los macizos vegetales, en este periodo, sólo se encuentran, y de forma muy esquemática, en los interpaneles del zócalo de los conjuntos Bil. 19 y 20. Un único conjunto [Bil. 5] presenta un zócalo formado por grandes compartimentos geométricos ligados por la unión de filetes. También es único el caso del conjunto Bil. 13, que muestra una zona inferior decorada con unas extrañas y coloridas bandas ondulantes sobre fondo negro, dispuestas en diagonal, con escasos paralelos tanto en la península itálica como en el mundo provincial.

En la transición hacia la zona media, tan sólo un conjunto [Arc. 1] recurre a un elemento decorativo propiamente dicho: un friso de fondo blanco que imita una cornisa a través de flores de loto estilizadas y motivos en $\mathrm{M}$. A este respecto, debemos concluir que este tipo de frisos es característico de las zonas de transición, ya sea del zócalo a la zona media, o de ésta a la superior.

El repertorio ornamental de la zona media es tan variado que es sumamente dificultoso incluso agrupar ornamentos del mismo tipo, sobre todo en lo concerniente a los interpaneles. Los candelabros continúan siendo el elemento más popular. Los presentes en el conjunto Bil. 19 imitan modelos metálicos -recurso, por tanto, no sólo propio de la primera mitad del s. I d. C.- mientras que los presentes en los conjuntos Arc. 2 y 5 y Bil. 8 son de tipo vegetal, especialmente los dos últimos que son prácticamente idénticos, de los que bien podríamos decir que son en realidad plantas arbóreas. Un subtipo, novedoso en este periodo, son los denominados candelabros torso, los cuales encontramos también en el conjunto Arc. 5, y en los conjuntos Arc. 1 y Bil. 19. Por último, debemos también citar los extraños candelabros tipo tirso, existentes en el conjunto Bil. 11.

Una de las características del Iv Estilo es la recuperación de las arquitecturas representativas del II Estilo. Podríamos pensar que sigue tal moda el conjunto Caes. 1 que contiene interpaneles decorados con columnas realizadas con pinceladas totalmente impresionistas; sin embargo, no ejercen de elementos sustentantes, por lo que no estamos 


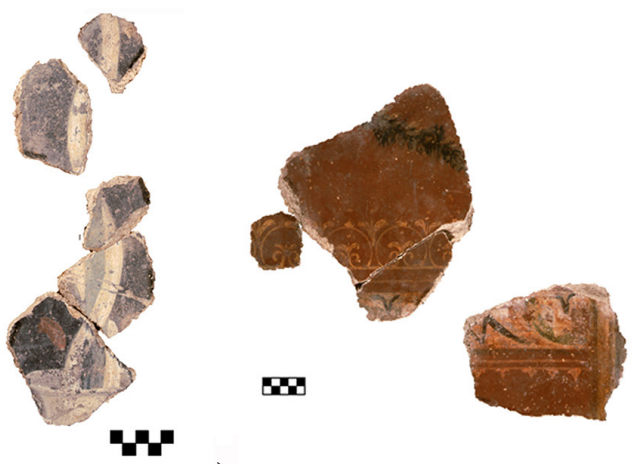

a)

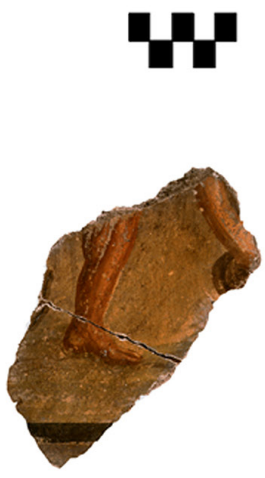

b)

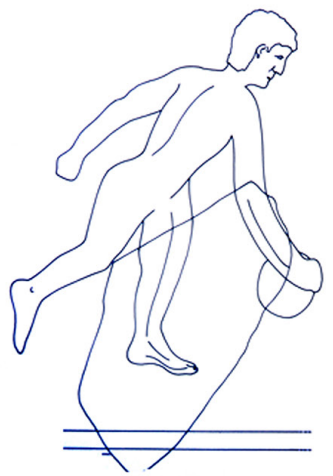

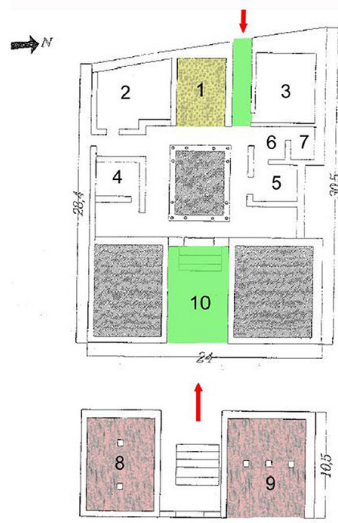
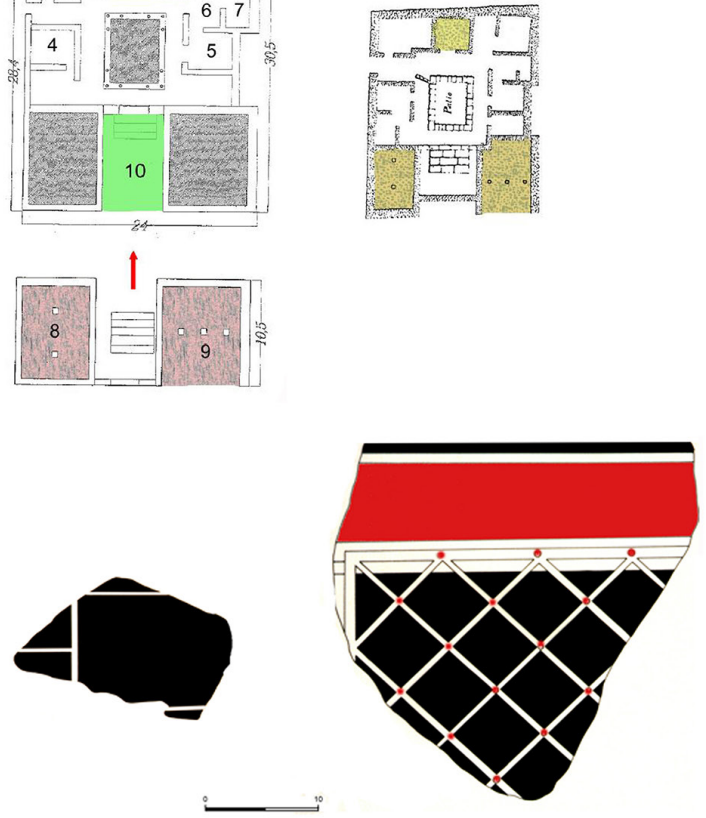

c)

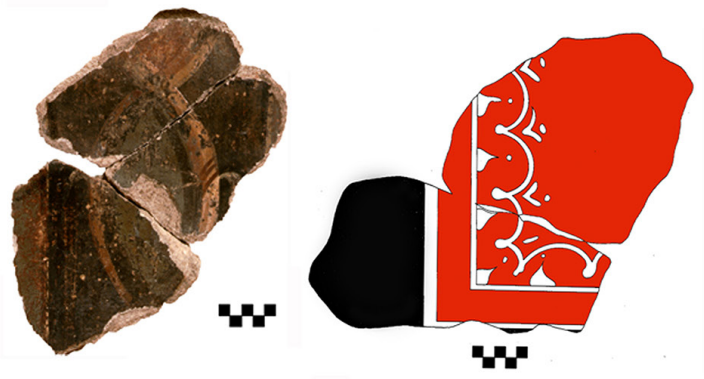

e)

d)

Fig. 10. Fragmentos de los conjuntos Arc. 1-5 procedentes de la Casa del Pretorio de Arcobriga (a partir de Guiral, 1991 y Guiral y Mostalac, 1992).

en disposición de hablar de la presencia de arquitecturas durante el Iv Estilo en el conventus Caesaraugustanus, algo realmente llamativo, como hemos podido apreciar al analizar los sistemas compositivos de este periodo. Por último, hallamos objetos colgantes decorando los interpaneles. Es cierto que ya hemos visto en el III Estilo pequeños elementos que pendían de candelabros [Bil. 12], pero ahora variados ornamentos -instrumentos sacerdotales, máscaras, coronas y cascos entre otros- aumentan 


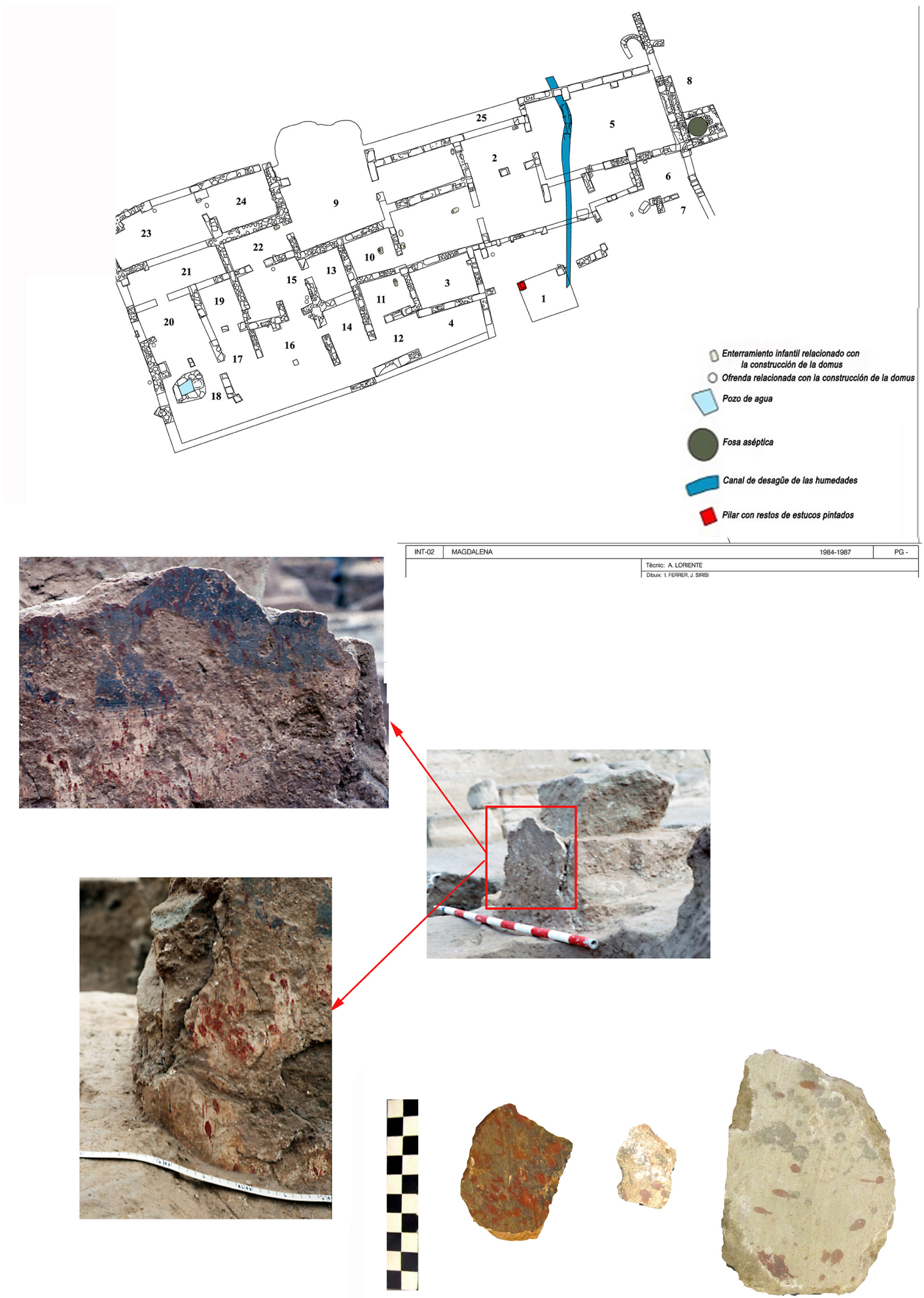

Fig. 11. Fragmentos procedentes del pilar de la Habitación 1 de Ilerda [Ile. 1] (fotog. de L. Íniguez y Ayto. de Lleida. Arxiu Arqueològic. Clara Lorencio). 
de tamaño, desplazan a los candelabros y adquieren verdadero protagonismo en esta zona de la pared [Bil. 19 y 20].

El repertorio ornamental de los paneles medios es también similar al visto para el III Estilo, aunque se introducen importantes novedades. Popular es la presencia de cenefas caladas de varios tipos: sucesión de triángulos equiláteros, de semicírculos tangentes, de círculos secantes, y de círculos [Bil.20]; sucesión de semicírculos secantes [Bil. 13]; sucesión de tres cuartos de círculo [Arc. 2]; festón con gotas de agua en su interior [Arc. 5]; cenefa opaca con sucesión de roleos contrapuestos, y cenefa opaca con sucesión de cuadriláteros [Caes. 1]. Es importante observar que las orlas canónicas se dan en los conjuntos fechados en las primeras décadas de la segunda mitad del s. I d. C., mientras que las opacas, las que no permiten ver el color de fondo -y se elaboran de forma mucho más barroca- se datan ya en periodo flavio.

No hallamos los filetes triples tan característicos del periodo anterior, pero se sigue recurriendo a los filetes simples blancos [Lab. 2, Bil. 8, 11, 19 y 20], negros [Bil. 6] y amarillos [Bil. 14], para encuadrar interiormente los paneles. Algunos continúan mostrando uno [Bil. 8] o varios puntos [Bil. 6], en sus ángulos. Caso aparte es la supuesta decoración republicana de Ercavica [Erc. 2], que presenta un doble filete vertical sin relleno en el interior. Por último, se documenta la representación de personajes situados en el tercio superior del panel que ornaban, como los amorcillos y el genio alado del conjunto Caes. 1. En el caso de la figura masculina identificada en el conjunto Arc. 2 posiblemente estuvo encerrada en un cuadrito. También debemos mencionar aquí la diosa Fortuna del larario pintado de Bilbilis [Bil. 17] que ocupa toda la superficie pictórica.

Escasas son las decoraciones que muestra el repertorio ornamental de la zona superior, principalmente porque casi no han llegado hasta nosotros fragmentos pertenecientes a esta sección. En cualquier caso, tres son los principales elementos constatados. En primer lugar, frisos de fondo blanco que, imitando una cornisa, muestran flores de loto invertidas y palmetas - mucho más esquematizadas que en el III Estilo-, acompañándose de pequeños

(C) Universidad de Salamanca ornamentos como bifolios, medias lunas y motivos en м [Bil. 19 y 20]. Una banda de varios colores ornamentada con elementos circulares en negro se observa en el conjunto Bil. 13. Por último, y sólo en el caso del conjunto Bil. 8, esta zona se adorna con una retícula de rectángulos a modo de casetones [Bil. 8].

En sólo dos de los conjuntos que remiten a techos podemos observar algún elemento decorativo, o bien rosetas formadas por dos cuerpos entrecruzados, en el centro de cada casetón [Bil. 21], o bien pequeños animales acompañados de guirnaldas [Arc. 4].

\section{Conclusiones: talleres y comitentes}

La pintura mural romana nos ofrece aspectos que van más allá de los meramente estilísticos. A través del estudio de las decoraciones podemos establecer si no conclusiones, al menos hipótesis que pueden ayudar a verificar o desechar las particularidades sociales y económicas de un periodo. Así pues, una vez analizadas las características de los conjuntos pictóricos tenidos en cuenta en este trabajo, es necesario ahora reflexionar sobre los artífices de los mismos, es decir, sobre los talleres de artesanos.

A continuación expondremos, basándonos en los criterios descritos, las conclusiones que hemos obtenido tras el análisis de los conjuntos pertenecientes al área objeto de nuestro estudio. Es evidente que, tanto por número de decoraciones como por el tiempo transcurrido entre la realización de unas y otras, más de un taller de artesanos trabajó en el conventus Caesaraugustanus durante el s. I d. C. Sin embargo, muchas veces, dada su fragmentación o estado de conservación, intentar dilucidar ciertas características de los operarios y, más aún, pretender individualizar equipos es una tarea sumamente difícil.

Comenzaremos hablando del origen de los pintores. Las decoraciones estudiadas, tanto las fechadas en el s. I d. C., como las de época republicana, denotan un origen itálico; hecho observable en el repertorio ornamental, en los esquemas compositivos y en la técnica con la cual fueron elaboradas. Es algo lógico, al menos para las decoraciones de los 
primeros momentos, ya que en la península ibérica no existió una tradición de pintura parietal prerromana, a excepción de algunos revestimientos sobre los fustes de columnas de edificios públicos o de carácter religioso.

Por tanto, no parece difícil adscribir las pinturas a un origen concreto en los primeros momentos. El problema lo encontramos a la hora de intentar identificar una posible 'segunda generación' de pintores -en la que ya tienen cabida artesanos locales-, como en la Galia (Barbet, 1982); o de 'talleres regionales', como en el conventus Carthaginensis (Fernández, 2008: 468). En ambos casos, los artesanos itálicos, después de haber creado escuelas y entrenado a los oriundos de la zona, darían paso a operarios locales que se expresarían con cierta originalidad sobre unas bases comunes aprendidas. Aunque se puede decir que en la Galia se documenta este hecho de forma más temprana, lo cierto es que en los dos territorios el fenómeno es manifiesto a finales del s. I y principios del s. II d. C. Cabe preguntarnos ahora si podemos observar lo mismo en el conventus Caesaraugustanus. Hemos de responder negativamente a esta cuestión. Ninguna de las decoraciones estudiadas, ni siquiera las datadas en época flavia, cuentan con rasgo alguno que permita apostar por esta hipótesis.

Es curiosa la conclusión a la que llegamos si comparamos lo expuesto con lo que ocurre con respecto a los pavimentos de este mismo territorio: en una fecha tan temprana como la primera mitad del s. I a. C., ya se constatan mosaístas locales que, habiendo aprendido el oficio y la técnica de operarios itálicos llegados con anterioridad al lugar, reproducen, no sin ciertas licencias y equivocaciones, el repertorio ornamental romano. Sin embargo, en pintura mural no observamos este fenómeno ni siquiera en un momento posterior. Las pinturas de época augústea, las de peor calidad en cuanto a ejecución de los distintos elementos ${ }^{16}$-recordemos que incluso

16 Excluimos de esta afirmación los conjuntos estudiados en Osca. Por otro lado, es evidente que en otras fases cronológicas también hay decoraciones de escasa calidad, pero se circunscriben a estancias secundarias. Su mala realización no se debe, por tanto, a la poca pericia del taller sino se pinta un candelabro al revés en el conjunto [Bil. 4]-, no pueden inducirnos a pensar que son operarios locales los que las realizan. Los motivos estudiados en las pinturas de esta etapa son nuevos, no se conocían con anterioridad a diferencia de los presentes en los pavimentos. Estos elementos no pueden viajar solos, sino que forzosamente tuvieron que ser talleres itálicos los que los trajeran consigo. Podemos concluir así que pertenecer a un equipo itálico no es sinónimo de calidad.

Teniendo todo lo anterior en cuenta, pasamos a continuación a enumerar los posibles talleres identificados, comenzando por la primera mitad del s. I d. C.:

- En el yacimiento bilbilitano se documenta la presencia de un taller operando en varias viviendas en los primeros momentos de la Era dada la similitud decorativa y/o técnica que presentan varios conjuntos [Bil. 9, 10 y 22] ${ }^{17}$.

- En Osca es evidente que el mismo equipo de artesanos realizó la decoración de los conjuntos Osc. 1 y 2, fechados en época augústea y pertenecientes además a la misma vivienda. No podemos conectar estas pinturas con el tercer conjunto estudiado [Osc. 3], del mismo periodo pero proveniente de otra domus, que además parece hallarse afectado por influencias decorativas galas.

- Hacia 20-25 d. C. individualizamos un taller en Celsa trabajando en todas las estancias que se erigen o repintan cuando se crea, por la unión de dos viviendas anteriores, la Casa c o Casa de los Delfines. En este caso, el equipo se identifica no tanto por la similitud ornamental entre habitaciones, sino por su particular forma de realizar el mortero, en el que hay presente un porcentaje ciertamente significativo de yeso - para jugar con los tiempo de fraguado de la cal- y una cantidad apreciable de arcilla rica en óxidos metálicos para provocar la fijación de pigmentos. Podemos concluir sobre este taller que contaba con la facultad de realizar ricas ornamentaciones para

más bien al escaso interés que éste puso para su realización debido a la propia funcionalidad o misión de la habitación.

17 Los talleres que trabajaron en el yacimiento bilbilitano ya fueron identificados por C. Guiral (Guiral y Martín-Bueno, 1996: 472-474). 
estancias de representación [Cel. 10], junto con otras elaboradas con menor cuidado, destinadas a ambientes secundarios [Cel. 12, 14 y 15]. Esto sin duda también debemos conectarlo con los gustos, mandatos y encargos del comitente, pero igualmente con la propia funcionalidad de las estancias, que era la que muchas veces dictaba la forma en que debía enlucirse.

En la segunda mitad del s. I d. C., se ha constatado, nuevamente por la similitud técnica y estilística de las decoraciones, la presencia de un mismo taller ${ }^{18}$ operando en dos de los lugares estudiados: Bilbilis, donde estos artesanos operan en varias construcciones del yacimiento [Bil. 8, 13, 19, $20 \mathrm{y}$ 21], y Arcobriga [Arc.1-5].

Tras un análisis de los talleres que trabajaron en el conventus Caesaraugustanus durante el s. I d. C., incidimos en varios hechos: su procedencia itálica, su diferente pericia, a pesar de este origen y según el periodo analizado -con la presencia, en general, de talleres de peor calidad en los primeros momentos de la Era y a finales de esta centuria- y la capacidad, en cualquier caso, para adaptarse a las necesidades, a la funcionalidad de las estancias y al gusto del dominus, combinando decoraciones banales o más bien prácticas con otras realizadas de forma cuidadosa y detallada, destacando, por supuesto, las ricas ornamentaciones para ambientes de representación.

Es evidente que, si complicado es averiguar las características formales de las pinturas del conventus Caesaraugustanus debido a la fragmentación y estado de conservación las piezas analizadas, imposible -y erróneo- resultaría llevar a cabo una interpretación social basándonos exclusivamente en estos restos pictóricos. No obstante, sí podemos plantear algunas hipótesis complementando los resultados obtenidos con los datos que nos ofrecen las estructuras arquitectónicas domésticas en las que estuvieron integrados los conjuntos -aunque hay que tener en cuenta que muchos se hallaron descontextualizados-.

18 Aunque hablamos de talleres, también debemos tener en cuenta no ya la itinerancia de los mismos - probada con los artesanos que se desplazaron entre Bilbilis y Arcobriga-, sino el dinamismo de los operarios, es decir, la posibilidad de que hubiera una suerte de intercambio de personal entre equipos (Pappalardo, 1995: 177-178).
En la zona campana, el análisis de las decoraciones pictóricas en las estructuras domésticas ha permitido llegar a conclusiones muy interesantes acerca de la sociedad que las concibió. En el periodo cronológico que nos ocupa, autores como V. Sampaolo (1992: 59-60), U. Pappalardo (2002-2003: 172) y L. Romizzi (2006: 24), entre otros, han corroborado el cambio político y cultural que aconteció con la llegada de Augusto, que se manifestó en una vuelta a unas bases morales concretas y que provocó una moda pictórica, el III Estilo, sobria y conservadora. Además, a través de la nueva iconografía se trató de evocar los exempla pietatis et virtutis acordes con la mentalidad del momento.

En un momento avanzado del periodo, desean sumarse a esa cúspide social los homines novi, un nuevo colectivo de origen humilde pero enriquecido por el éxito de sus actividades comerciales, principalmente, y por haberse visto favorecidos por diversas alianzas y políticas de adopción. Esta clase emergente querrá equipararse a las viejas élites imitándolas, fenómeno que se refleja de manera muy acusada en la decoración de sus viviendas, siendo el periodo neroniano-flavio cuando esta suerte de nuevos ricos vive su momento de mayor esplendor.

Cabe cuestionarnos si todo lo expuesto tiene su reflejo en el mundo provincial. La etapa augústea en el conventus Caesarangustanus supone un periodo de afirmación de la cultura romana y de integración indígena en la misma. El repertorio ornamental analizado no nos permite conocer si aquí se dio el mismo fenómeno descrito para el área campana. Ahora bien, los conjuntos de este periodo disponen de una gama cromática y de un esquema compositivo, ambos totalmente estudiados y acordes con la sobriedad impuesta por la vuelta a unos valores morales antes referidos.

Por otro lado, no debemos olvidar que esta cuestión se complica en el mundo provincial donde, a las mutaciones sociales documentadas en la península itálica, hay que añadir el proceso de integración y adhesión a la nueva cultura de los indígenas romanizados. Pinturas de este periodo, como la presente en el techo de la habitación 12 de la Casa de los Delfines de Celsa [Cel. 12], y algunas bilbilitanas, 
como la hallada en la estancia [H. 27] de la Domus 3 [Bil. 3], la exhumada en el sector CIV [Bil. 12] y la mayoría de las encontradas en las termas [Bil. 19, 20 y 21], citando sólo los casos paradigmáticos, presentan unas escenas y un repertorio ornamental con un simbolismo en plena consonancia con la cultura romana, que nos incita a plantearnos, por un lado, si fueron comitentes de origen itálico los que encargaron estas decoraciones, celosos guardianes de las tradiciones de su lugar de origen; o si por el contrario lo hicieron indígenas romanizados deseosos de manifestar explícitamente su ligazón a la cultura romana.

En el caso de Celsa, tanto el estudio de su planta como, sobre todo, los hallazgos epigráficos en la citada vivienda (Cisneros, 1998: 15) denotan un origen itálico de los comitentes. Los casos bilbilitanos son más complejos. La Domus 1, integrada en la misma Insula que la Domus 3 y decorada con pinturas fechadas en época republicana y augústea, también estuvo ocupada por esos primeros colonos itálicos llegados al enclave. Sin embargo, no podemos decir lo mismo de la Domus 3. Su repertorio ornamental muestra una simbología sólo comprensible dentro de la cultura romana, pero se observa una evidente ostentación propia de alguien con verdadera pretensión de manifestarla. Una ornamentación de estas características en la que está implícito el deseo de mostrar la riqueza que se poseía, y que creemos que debemos extrapolar a algunos de los conjuntos fechados en este periodo -en el ocaso del III Estilo- [Bil. 12] o en el inmediatamente posterior-algunos de los encuadrados en un Iv Estilo canónico- [Bil. 19-20], sólo pudo pertenecer bien a un miembro de la élite romana-como hemos visto en Celsa-, bien a un propietario integrante de esas clases emergentes enriquecidas o, sin excluir esta opción, a un indígena romanizado que quisiera equipararse a aquel selecto grupo. No olvidemos que hallamos conjuntos con similares características en la Casa del Pretorio de Arcobriga [Arc. 1-5], gran estructura arquitectónica cuyos propietarios también debieron gozar de una posición económica y, con toda probabilidad, social, elevada.

Creemos que a finales de la centuria ya no debemos hablar de itálicos o indígenas romanizados.
Sí que puede seguir existiendo un deseo de mostrar las posibilidades económicas del dominus, como se desprende de las paredes del triclinio exhumado en la cl Añón de Zaragoza [Caes. 1], pero, en definitiva, la cultura romana ya no era nueva ni diferente.

En definitiva, la pintura mural romana en los espacios domésticos del conventus Caesaraugustanus durante el s. I d. C. es la manifestación de la asimilación paulatina y no violenta de la nueva cultura imperante.

\section{Bibliografía}

Barbet, A. (1982): "La diffusion du ine style pompéien en Gaule", Gallia, 40 (1), pp. 53-82.

BARBET, A. (1985): La peinture murale romaine. Les styles décoratifs pompéiens. Paris: Picard.

BARBET, A. (2008): La peinture murale en Gaule romaine. Paris: Picard.

Bastet, F. L. y De Vos, M. (1979): Il terzo stile pompeiano. Gravenhage: Nederlands Instituut te Rome.

Belot, E. (1986): "Les productions de l'artisanat pictural gallo-romaine à Nemetacum". En Arras Nemetacum et la partie méridionale de la cité des Atrébates. Catalogue d'exposition (Arras, 28 mai-19 août 1986). Madrid: General de Arqueología y Etnografía, pp. 54-66.

Beltrán, F. (2000): "La vida en la frontera". En BeLtrán, F.; Martín-Bueno, M. y Pina, F. (dirs.): Roma en la cuenca media del Ebro. Zaragoza: Caja de Ahorros de la Inmaculada, pp. 45-62.

Beltrán, F.; Martín-Bueno, M. y Pina, F. (dirs.) (2000): Roma en la cuenca media del Ebro. Zaragoza: Caja de Ahorros de la Inmaculada.

Beltrán, M. y Mostalac, A. (1996): "La casa romana en Hispania. Estado de la cuestión”. En Borgard, P. (dir.): La maison urbaine d'époque romaine en Gaule Narbonnaisse et dans les provinces voisines. Actes du colloque (Avignon, 1994). Avignon: Service d'Archéologie du Conseil Génerale de Vaucluse, pp. 61-71.

Beltrán, M. y Mostalac, A. (2008): "La Colonia Lepida/Celsa y Salduie: sus testimonios arqueológicos durante el segundo triunvirato y comienzos del Imperio". En García-Bellido, M. P.; Mostalac, A. y Jiménez, A. (eds.): Del Imperium de Pompeyo a la Auctoritas de Augusto. Homenaje a Michael Grant. Anejos de Archivo Español de Arqueología, XLVII. Madrid, pp. 107-127. 
Cisneros, M. (1998): "El empleo privado de mármol en el valle del Ebro: la Colonia Victrix Iulia Lepidal Celsa (Velilla de Ebro, Zaragoza)", Caesarangusta, 74, pp. 13-36.

Clarke, J. R. (1987): "The early third style at the Villa of Oplontis", Mitteilungen des Deutschen Archaeologischen Instituts. Roemische Abreilung, 94, pp. 267294.

De Vos, M. (1976): "Scavi Nuovi sconosciuti (I. 9. 13): pitture e pavimenti della Casa di Cerere a Pompei", Mededelingen van het Nederlands Historich Instituut te Rome, 38, pp. 37-75.

Fernández DíAz, A. (2008): La pintura mural romana de Carthago Noua. Evolución del programa pictórico a través de los estilos, talleres y otras técnicas decorativas. Murcia: Museo Arqueológico de Murcia.

Fincker, M.; Guiral, C.; Magallón, M. A.; Navarro, M.; Rico, C. y Sillières, P. (2013): "La seconde phase de monumentalisation urbaine: la Curie". En Magallón, M. A. y Sillières, P. (eds.): Labitolosa. Une cité romaine de L'Hispanie Citérieure. Bordeaux, pp. 213-252.

Galve, M. P.; Magallón, M. A. y Navarro, M. (2005): "Las ciudades romanas del valle medio del Ebro”. En Sillières, P. (dir.): L'Aquitaine et l'Hispanie Septentrionale à l'époque julio-claudienne. Organisation et explotaition des espaces provinciaux. IV Colloque Aquitania (Saintes, 2003). Bordeaux: Éditions de la Fédération Aquitania sup. 13, pp. 168-211.

Guillaud, J. (1990): La peinture à fresque au temps de Pompei. Paris: Guillaud éditions.

Guiral, C. (1991): "Pinturas romanas procedentes de Arcobriga II", Caesarangusta, 68, pp. 151-204.

Guiral, C. e ÍñIguez, L. (2011): "Alta et versicolor Bilbilis", Salduie, 11, pp. 73-96.

Guiral, C. y Martín-Bueno, M. (1996): Bilbilis I. Decoración pictórica y estucos ornamentales. Zaragoza: Institución Fernando el Católico.

Guiral, C. y Mostalac, A. (1992): "La pintura mural romana de Arcobriga (Monreal de Ariza, Zaragoza)". En Jiménez, J. L. (ed.): I Coloquio de pintura mural romana en España (Valencia-Alicante, 1989). Valencia: Ministerio de Cultura, pp. 99-105

Guiral, C. y Mostalac, A. (1993): "Influencias itálicas en los programas decorativos de cubicula y triclinia de época republicana y altoimperial en España. Algunos ejemplos representativos", Espacio, Tiempo y Forma, Serie I. Prehistoria y Arqueologia, 6, pp. 365-392.

Guiral, C. y Mostalac, A. (2011): "Programas decorativos de época republicana en el valle medio del Ebro: conservadurismo y progresismo". En Balmelle, C.; Eristov, H. y Monier, F. (dirs.): Décor et architecture en Gaule. Entre l'Antiqiuté et le haut Moyen Âge. Mosaïque, peinture, stuc. Actes du colloque international (Université de Toulouse II-Le Mirail, 2008). Bordeaux: Aquitania sup. 20, pp. 597-609.

Guiral, C.; Mostalac, A. y Cisneros, M. (1986): “Algunas consideraciones sobre la imitación del mármol moteado en la pintura romana en Espaná, Boletín del Museo de Zaragoza, 5, pp. 259-288.

IÑigueZ, L. (2015): "Las musas en Bilbilis". En ZimmerMAN, N. (ed.): Antike Malerei zwischen Lokalstil und Zeitstil. Archaeölogische Forschungen, 23. Wien, pp. 621-625.

ÍñIguez, L.; SÁenz, C. y Martín-Bueno, M. (2011): "Novedades pictóricas del Municipium Augusta Bilbilis: el edificio cIv", Espacio, Tiempo y Forma, Serie I. Prehistoria y Arqueología. Nueva época, 4, pp. 209-229.

Ling, R. y L. (2005): The Insula of the Menander at Pomepeii. Volume II: the decorations. Oxford: Clarendon Press.

Mostalac, A. (1996): "La pintura romana en España. Propuesta cronológica del Tercer Estilo", Anuario de la Universidad Internacional Sek, 2, pp. 11-27.

Mostalac, A. y Beltrán, M. (1994): Colonia Victrix Iulia Lepida Celsa (Velilla de Ebro, Zaragoza). II, Estratigrafía, pinturas y cornisa de la "Casa de los delfnes". Zaragoza: Gobierno de Aragón.

Mostalac, A.; Beltrán, M. y Corral, M. a R. (2007): "La decoración pictórica del triclinio de la casa romana de la calle Añón de Zaragoza (España)". En Guiral, C. (ed.): Circulación de temas y sistemas decorativos en la pintura mural antigua. Actas IX Congreso Internacional Association Internationale pour la Peinture Murale Antique (Zaragoza-Calatayud, 2004). Zaragoza: Gobierno de Aragón-uned, pp. 255-262.

Mostalac, A. y Guiral, C. (1987): "La pintura romana de Caesarangusta: Estado actual de las investigaciones", Boletín del Museo de Zaragoza, 6, pp. 181-196.

Pappalardo, U. (1995): "La bottega della Villa Imperiale a Pompei", Mededelingen van het Nederlands Instituut te Rome, 54, pp. 176-191.

Pappalardo, U. (2002-2003): "La influencia de la ideología augústea en la decoración de Pompeya y Herculano", Lucentum, 21-22, pp. 171-170.

Romizzi, L. (2006): Programmi decorativi di III e IV stile a Pompei. Un'analisi sociológica ed iconológica. Napoli: Loffredo. 
Rubio, R. y Valero, M. A. (2007): "Intervención arqueológica en Ercavica: campańas 2003-2005”. En Millán, J. M. y Rodríguez, C. (coords.): Arqueología de Castilla La Mancha. I Jornadas (Cuenca, 2005). Cuenca: Edic. Univ. de Castilla La Mancha, pp. 432-444.

Sáenz, C. y Martín-Bueno, M. (2010): "El Larario de la Casa del Ninfeo de Bilbilis (Calatayud-Zaragoza-España)". En Bragantini, I. (ed.): Atti X Congresso internazionale dell'Association Internationale pour la Peinture Murale Antique (Napoli, 2007). Napoli: Univ. degli Studi di Napoli “L'Orientale”, pp. 823-826.
Sampaolo, V. (1992): "La decorazione pittorica in età imperiale”. En Zevi, F. (dir.): Pompei II. Napoli: Banco di Napoli, pp. 59-83.

Schefold, K. (1953-54): "Pompeji unter Vespasian", Mitteilungen des Deutschen Archaeologischen Instituts. Roemische Abteilung, 60-61, pp. 107-125.

Uribe, P.; Hernández, J. A. y Bienes, J. J. (2011): "La edilicia urbana privada en Los Bañales: estado de la cuestión". En ANDreu, J. (ed.): La ciudad romana de Los Bañales (Uncastillo, Zaragoza): entre la historia, la arqueología y la historiografía. Zaragoza: Caesaraugusta 68, pp. 241-260. 